\title{
Firebug! Dissociative Identity Disorder? Malingering? Or ...? An Intensive Case Study of an Arsonist
}

\author{
Richard J. Loewenstein ${ }^{1}$ (i) \\ Received: 24 December 2019 / Accepted: 23 April 2020 / Published online: 23 June 2020 \\ (C) The Author(s) 2020
}

\begin{abstract}
Courts struggle with questions of how to assess competency to stand trial (CTS) and not guilty by reason of insanity (NGRI) in dissociative identity disorder (DID). Concerns about CTS include dissociative amnesia and unpredictable switching behaviors that could cause inconsistent information transfer across self states, with the defendant unable to access important legal information about his/her defense and to collaborate with his/her attorney; DID defendants could not conform their conduct to the law or know right from wrong due to dissociative amnesia, the seemingly independent actions of self states, and the disruption of reality testing by switching. The author presents the case of a woman charged with both a witnessed and an unwitnessed burglary and arson, the latter at the home of her former therapist. The author was the fourth forensic evaluator in the case. Disagreements included whether the defendant met diagnostic criteria for DID or was malingering, and whether she was CTS and/or NGRI. In clinical work with DID, "the whole human being" is held responsible for all behavior, despite reported amnesia or lack of subjective agency. The Discrete Behavioral States (DBS) model of DID avoids reification of the DID self states and their conflation as separate "people." This model supports evaluating the defendant at the level of specific self states, the self-state system, and that of the whole human being. The author concluded that the defendant met diagnostic criteria for DID and also was malingering its severity. She was competent to stand trial and legally sane.
\end{abstract}

Keywords Dissociative identity disorder · Forensics · Assessment · Criminal responsibility · Competence to stand trial · Malingering

\section{Introduction: the Story Begins}

On a rainy, chilly, early fall morning in a small university town, a young man was reading in his bedroom upstairs at his parents' comfortable home in a wooded area of widely separated houses. He did not respond when he heard a knock at the door. And he did not respond when he heard the door open - people often left doors unlocked here - and a middleaged female voice called out to see if anyone was home. Soon, he heard banging downstairs, smelled smoke, and saw the reflection of flickering flames. He raced downstairs and saw a short, stocky, middle-aged woman standing in his kitchen, throwing towels and linens on top of the stove-with all the burners turned to high. He saw smoke coming from a smoldering living room couch.

Richard J. Loewenstein

rjloewensteinmd@gmail.com

1 Department of Psychiatry, University of Maryland School of Medicine, Stevenson, MD 21152-9998, USA
He grabbed the woman by the left arm and shouted, "What are you doing?" She answered, "I'm sick!" Juggling the phone to call 911 and trying to put out the fire, he dropped her arm. The woman walked calmly out the door, climbed into a blue truck, and drove away. The young man gave her description and the license plate number of the truck to the 911 operator. Ultimately, the fire was contained and the man was unharmed.

Two additional arson fires were set in the vicinity that morning. One burned a home to the ground, leaving virtually no evidence of a perpetrator. The other was set at the home of Ms. Brown, ${ }^{1}$ a psychotherapist who worked at the University Medical Center Outpatient Psychiatry Clinic, in town. The arsonist set three fires in her basement, causing major damage there and to the heating and plumbing systems, as well as an electrical short, with extensive smoke damage throughout the house. The arsonist opened and rummaged through many drawers and closets and must have seen the three pet cats and a pet

\footnotetext{
${ }^{1}$ In this report, all names, including those of DID self states, have been changed, as well as details of the case altered for privacy. All information reported comes from the public court record.
} 
bird that died from smoke damage. Additionally, the arsonist used a vehicle to slowly ram the garage door, leaving a dent and blue paint fragments. No other building on the property, including a working horse barn, was damaged. This fire was not discovered until later in the day, when Ms. Brown and her husband returned home from work.

The license plate of the blue truck was rapidly traced to the family of Ms. Doris Neely, a 50-year-old woman who lived with her husband in a rural area outside town. When the police called, Ms. Neely answered the phone and identified the truck as her husband's, which she had been driving that morning. However, she was baffled by the allegation of wrongdoing. She gave the phone to her husband, who confirmed ownership of the truck and agreed to bring his wife in for police interviews.

Ms. Neely entered police headquarters accompanied by her husband, hobbling on the crutches and wearing the leg and back braces that she virtually always used when ambulating outside her home. Hidden in the parking lot, the young man who witnessed the fire-setting identified Ms. Neely as the arsonist. The police officer carrying out the initial videotaped interview later described Ms. Neely's demeanor as "calm, cool, and collected." After the officer relayed the witness's description of Ms. Neely setting the fire in his home, her first recorded comment was, "Did he say I was using my crutches?" Throughout the interview, she denied any memory of the fire-setting, only recalling doing errands, getting fast food at a drive-in, eating in her car, and stopping at a stop sign on the way home. She denied recall of anything more until arriving home. When pressed about the apparent gap of about three hours in her account, her husband explained that for the last 25 years his wife carried the diagnosis of dissociative identity disorder (DID) and had been in and out of treatment for this condition with many different providers. He stated that this disorder caused his wife to have memory lapses and behavior she did not remember.

After the arson fire at Ms. Brown's home was reported, the police learned that Ms. Neely had been a psychotherapy patient of Ms. Brown at the university psychiatric clinic for approximately three years. About six months prior to the arson, Ms. Brown had terminated Ms. Neely's treatment at the behest of clinic administration due to multiple disruptions Ms. Neely created at the clinic.

Ms. Neely was arrested and charged with Attempted FirstDegree Arson and Burglary-Occupied Home for the witnessed fire-setting. Ms. Neely described no memory for it and claimed she could not have done it because she did not recall it. She was charged with First-Degree Arson and Burglary for the fire at Ms. Brown's home. She vigorously denied setting this fire, insisting that, "we had a good relationship. Why would I have done that? I only went there [to the therapist's house] one time." Because of her perceived physical disability and her husband's standing in town, Ms. Neely was released into his custody pending arraignment scheduled for the following Monday morning.

So, began a three-year process to determine the legal impact of Ms. Doris Neely's mental state on her competence to stand trial and on her insanity defense (see Table 1 for legal standards for CTS and NGRI/NCR). Four different forensic psychiatrists performed evaluations, the last being the author, who performed the second court-ordered forensic evaluation, as stipulated by both the attorney for the state and Ms. Neely's attorney.

\section{Conceptual Framework for Understanding DID}

This framework underlies my approach to clinical and forensic work with DID and was the foundation of my assessment of Ms. Neely. The following discussion describes conceptualization and techniques supported by outcome studies of DID treatment, as well as expert consensus (Brand et al., 2011; Brand et al., 2013; Brand, Webermann, Snyder, \& Kaliush, 2019). This structure provides a rigorous way to approach forensic assessment of DID and to address many of the conundrums that have vexed the legal system grappling with forensic issues regarding the disorder (Allison, 1984; Armstrong, 2001; Behnke, 1997a, 1997b; Kluft, 1987c; Orne, Dinges, \& Orne, 1984; Sinnott-Armstrong \& Behneke, 2001; Watkins, 1984). In this work, I use the term "self state" instead of the DSM-5 "personality state or identity

Table 1 Standards for competence to stand trial and not guilty by reason of insanity

1. The formal standard for competence to stand trial is based on the findings in US v. Dusky:

"... Whether he [the defendant] has sufficient present ability to consult with his lawyer with a reasonable degree of rational understanding and whether he has a rational as well as a factual understanding of the proceedings against him.” [362 U.S. 402, 80 Sct 788 (1960).

2. Test of insanity in criminal cases

(a) The test when used as a defense in criminal cases shall be as follows:

(1) A person is not responsible for criminal conduct if at the time of such conduct as a result of mental disease or defect, he lacks adequate capacity either to appreciate the criminality of his conduct or to conform his conduct to the requirements of law.

(2) The term "mental disease or defect" does not include an abnormality manifested only by repeated criminal or otherwise antisocial conduct. The term "mental disease or defect" shall include congenital and traumatic mental conditions as well as disease.

(b) The defendant shall have the burden of proof in establishing insanity as an affirmative defense by a preponderance of the evidence.

NGRI/NCR standards may vary between states. The standard reported here is a common one and was the standard in Ms. Z's state 
state." I view "self state" as more phenomenologically accurate than other terms for the personified states in DID. I avoid terminology commonly used in the literature such as "alter," "part," "dissociative part of the personality," etc. that can result in reifying the self states (see Loewenstein, Frewen, \& Lewis-Fernández, 2017, for fuller discussion of terminology for DID states).

DID is a paradox. It is understood to be both a severe mental illness and a developmental adaptation that preserves important types of resilience through psychobiological sequestration of overwhelming traumatic experiences.

\section{DID: a Posttraumatic Developmental Disorder}

DID is best conceptualized as a childhood-onset posttraumatic developmental disorder. In the developmental model of DID, the disorder is not viewed as the "shattering" or "fragmentation" of a "core personality." Instead, based on Putnam's Discrete Behavioral State (DBS) model (Putnam, 2016; Trickett, Noll, \& Putnam, 2011), Kluft's Four-Factor Theory (Kluft, 1985b), and the Trauma-Related Altered State of Consciousness (TRASC) model of Lanius and Frewen (2015), DID is viewed as an alternative developmental pathway where the traumatized child fails to develop a consistent sense of self across behavioral/emotional states and contexts. DID has been diagnosed in young children, adolescents, adults, and geriatric individuals (Armstrong, Putnam, Carlson, Libero, \& Smith, 1997; Kluft, 1985a, 1985b, 2007b; Putnam, Hornstein, \& Peterson, 1996; Putnam, 1997).

The Discrete Behavioral State (DBS) model of DID is based on observational studies demonstrating discrete behavioral states in the patterning and organization of normal early childhood behavior and affect regulation (Putnam, 1997, 2016). In the dissociative child, discrete behavioral states do not become integrated and coordinated during development, as normally occurs. Instead, unbearable memories and affects are psychobiologically sequestered through processes such state-dependent learning. Repeated traumatic experiences, combined with disturbed caretaker-child attachment and parenting, disrupt the normal metacognitive processes involved in developing a subjectively unified self. These critical processes, prominent between the ages of 1 and 6 , establish the child's capacity to integrate different experiences of self that normally occur across different contexts and emotional states (Putnam, 1997, 2016). The dissociative child usually receives unreliable or no comforting or restorative interactions from caretakers to counterbalance repeated extreme states, further inhibiting normal development of a unified sense of self, as well as profoundly impairing the capacity for emotional regulation (Kluft, 1985b; Silberg, 2004, 2013). The child has to find ways to manage overwhelming experiences, often by entering a shutdown state (Schalinski \& Teicher, 2015). As development proceeds through childhood and adolescence, the result is an individual with relatively independent senses of self, often in conflict with one another. Myriad factors determine the subsequent shaping of the subjective and presentational aspects of the DID self states (see below).

\section{Trauma}

DID patients have the highest rates of childhood trauma, particularly combined sexual, physical, and emotional abuse, of any clinical population studied (Hornstein \& Putnam, 1992; Lewis \& Yeager, 1996; Loewenstein et al., 2017; Putnam et al., 1996; Spiegel et al., 2011). Rigorous retrospective studies, as well as studies of maltreated children, have documented the childhood traumas experienced by DID individuals, including specific physical injuries sustained in childhood, and traumas for which the individual denied any recall (Armstrong, 2001; Feldman, Mallouh, \& Lewis, 1986; Hornstein \& Putnam, 1992; Kluft, 1997; Lewis \& Yeager, 1996; Lewis, Yeager, Swica, Pincus, \& Lewis, 1997; Putnam et al., 1996). Also, like others afflicted with childhood sexual abuse, various forms of revictimization - intimate partner violence, adult sexual assault, trafficking - are common in this population (Cooper, Kennedy, \& Yuille, 2001; Middleton, 2013; Salter, 2017; Snyder, 2018; Webermann, Brand, \& Kumar, 2017).

The types of trauma described in the Adverse Childhood Experiences (ACE) Study (Felitti \& Anda, 2010) are common in the histories of individuals diagnosed with DID. Many come to treatment manifesting a number of the negative outcomes associated in the study with increasing numbers of ACEs. These include PTSD; depression; high rates of suicidal acts and non-suicidal self-injury (NSSI); addictions including drugs, alcohol, and gambling; morbid obesity; intimate partner violence; hearing voices; childhood autobiographical memory disturbances; multiple psychiatric co-morbidities; and medical illnesses such as STDs, chronic pain, and heart, lung, liver, gastrointestinal, and auto-immune diseases (Brand, Sar, et al., 2016; Brown et al., 2007; Classen, Palesh, \& Aggarwal, 2005; Dell, 2013; Foote, Smolin, Neft, \& Lipschitz, 2008; Imperatore et al., 2017; LeBouthillier, McMillan, Thibodeau, \& Asmundson, 2015; Myrick, Brand, \& Putnam, 2013; Park et al., 2016;; Pilton, Varese, Berry, \& Bucci, 2015; Putnam, Harris, \& Putnam, 2013; Spiegel et al., 2011; Webermann, Myrick, Taylor, Chasson, \& Brand, 2016, Webermann et al., 2017).

\section{Resilience}

Psychological assessment studies of adult DID patients illustrate the protective and resilience-generating effects of early life dissociation, as well as severe dissociative and posttraumatic interference in testing. Severely dissociative individuals frequently show idiosyncratic posttraumatic activation to 
testing, such as going into a flashback while reacting to a Rorschach ink blot or performing poorly on a WAIS subtest due to a unique posttraumatic reminder. For the Rorschach, this required developing a specific variable, the trauma content score (TC); DID individuals showed a mean TC score of at least 50\% (Armstrong, 1991; Brand, Armstrong, Loewenstein, \& McNary, 2009). Testing also showed dissociative defenses against posttraumatic intrusions. Subjects would start to have posttraumatic reactivity during their responses and then rapidly became hyperfocused on small areas of the Rorschach blot, seemingly in a dissociative trance state, and provided complex, emotionally detached descriptions (Armstrong, 1994). When not posttraumatically overwhelmed, DID subjects demonstrated good reality testing, an ability to take distance from cognitive distortions, a capacity for attachment, a sense of humor, creativity, excellent self-observing capacity, and hope (Brand, Armstrong, \& Loewenstein, 2006; Brand, Armstrong, et al., 2009). DID individuals demonstrate marked psychological and cognitive complexity, distinguishing them from psychotic, borderline personality disorder (BPD), and combat PTSD subjects (Armstrong, 1991; Brand, Armstrong, et al., 2006; Brand, Armstrong, et al., 2009).

Individuals with DID show a broad range of functional capacity. On one end of the spectrum, DID has been shown to meet criteria for a serious mental illness, with high rates of disability (Johnson, Cohen, Kasen, \& Brook, 2006; Mueller-Pfeiffer et al., 2012; Spiegel et al., 2011). Comorbidities like PTSD and depression affect close to $100 \%$ of DID individuals, along with high rates of substance abuse, somatic symptom disorders, and BPD features. Individuals with DID have substantial rates of suicidal, self-destructive, and high-risk behaviors, often requiring treatment at increasingly restrictive levels of care (Spiegel et al., 2011). However, as in bipolar disorder, the expert consensus is that there is a broad range of functioning in DID, with some individuals highly achieving in professional, and even personal, life and rapidly responding to outpatient treatment alone (International Society for the Study of Dissociation et al., 2011; Kluft, 1986, 1990a, c, 1994b).

In order to diagnose, evaluate, and treat DID, one most hold both levels of this dialectic in mind: this is a human being with a profound mental illness and with significant resilience and adaptive resources. One should not romanticize the resilience and overlook the pathology, nor only attend to the pathology and blind oneself to the strengths found in many DID individuals.

\section{Making Sense of Self States}

The DID individual is not a collection of separate, static "people" acting independently. DID self states can be represented in different ways over time depending on many developmental and psychological influences (Kluft, 1985b, 1991, 2005, 2006, 2007a; Putnam, 1997, 2016). Outward presentation to others, if any, may vary as well. Many DID self states are only experienced intrapsychically (Kluft, 1991). Fundamentally, DID self states can be conceptualized as relatively separate senses of self (often including a body image), organized around a prevailing affect, a set of state-dependent autobiographical memories, and a limited behavioral repertoire (Kluft, 1988; Putnam, 1988). Following Kluft (1988): "[A DID self state] functions both as a recipient, processor, and storage center for perceptions, experiences, and the processing of such in connection with past events and thoughts, and/or present and anticipated ones as well. It has a sense of its own identity and ideation, and a capacity for initiating thought processes and actions ... which may be behaviorally enacted with noteworthy role-taking and role-playing dimensions and sensitive to intrapsychic, interpersonal, and environmental stimuli..." (page 51). DID self states may be experienced with "delusional separateness"-with some self states insisting "they" do not inhabit the same body nor will they be affected by what happens to it (even death) - and/or "delusional disorientation to current circumstances"-with some states maintaining "they" do not exist in the same time and place as the actual human being.

To understand DID, one must recognize that the mind of the DID individual is subjectively structured as a complex, dynamic, adaptive self-state system that, beginning in early childhood, evolves developmentally. Putnam (1997, 2016) conceptualizes the core phenomenology of DID as the state of multiple states, which can subjectively reconfigure in varying ways over time. Armstrong (2001) uses the simile of understanding light as both particles and waves. She conceptualizes DID both at the level of specific self states and simultaneously at the level of the dynamic self-state system. There is a third level of conceptualization: that of the "whole human being" across all states and the self-state system. For example, in the pharmacological treatment of DID, medications are unlikely to be effective unless the symptoms of a co-morbid disorder, e.g., a mood disorder, are experienced across the whole mind, not just in specific self states (International Society for the Study of Dissociation et al., 2011; Loewenstein, 1991b, 2005). In assessing behaviors in the DID individual, one must consider that a number of different self states, in coordination and/or in conflict, account for them, not a revolving door of independently acting "people." In this regard, it is critical to focus on DID as a self-state system, not an assemblage of relatively independent, recurring entities with stable characteristics.

The personality of the DID individual is made up of all the DID self states as well as all the non-trauma/dissociation factors that affect development of the human personality (International Society for the Study of Dissociation et al., 2011). Individual self states cannot have "separate" 
personality disorders, as was suggested by one of the forensic examiners in this case. The latter should be diagnosed as comorbid with DID only if the personality disorder symptoms occur across the whole mind - an assessment of which may require longitudinal observation (International Society for the Study of Dissociation et al., 2011). Usually, as with bipolar disorder, the DID individual needs to be stabilized from dyscontrolled dissociative and PTSD symptoms before a personality disorder can be diagnosed.

Several studies of borderline personality disorder (BPD) in DID individuals have found that meeting DSM-5 BPD criteria is an indicator of decompensation in DID, with severely dyscontrolled dissociative and PTSD symptoms (Ross, Ferrell, \& Schroeder, 2014; Sar, Alioglu, \& Akyuz, 2014). Frequently, once the DID individual is symptomatically stabilized, many of the BPD symptoms remit (Armstrong, 1991; Boon \& Draijer, 1993; Laddis, Dell, \& Korzekwa, 2017; Ross et al., 2014; Sar, Alioglu, \& Akyuz, 2017). Many putative BPD individuals, when studied with symptom screening and diagnostic measures for dissociation and DD, will be diagnosed instead with DID, with the BPD symptoms manifestations of the severity of the DD and PTSD symptoms (Sar, Alioglu, \& Akyuz, 2017; Sar, Sar, Alioglu, Akyuz, Tayakisi et al., 2017). Many DSM-5 diagnostic criteria for BPD overlap with, and may be confused with, the phenomenology of DID. These include identity disturbance; high-risk, selfdestructive behavior and suicidal behavior; "affective instability" which can be mistakenly applied to rapid DID state shifts; and of course, dissociative symptoms. Self-destructive and suicidal behavior are better accounted for as outcomes of ACEs and dissociation rather than personality disorders (Dube et al., 2001; Felitti \& Anda, 2010; Ford \& Gomez, 2015; Webermann et al., 2016; Weierich \& Nock, 2008). In one study, in a logistic regression comparing DD, PTSD, BPD, and substance abuse, where trauma was controlled, a DD diagnosis remained as the only significant predictor of multiple suicide attempts (Foote et al., 2008).

Many DID individuals do not have a pattern of intense, unstable relationships. As in this case history of Ms. Neely, who had been married for almost 30 years, many DID individuals have stable, long-term relationships, albeit many are abusive or highly dysfunctional (Snyder, 2018; Webermann et al., 2017). Many DID individuals are profoundly avoidant of relationships because of their long histories of interpersonal betrayal, abuse, and exploitation. DID individuals frequently do not display the classical "idealization/devaluation" transference. Their transferences are primarily traumatic, with the expectation of exploitation or blindness to exploitation by the therapist, among other posttraumatic relational themes (Kluft, 1994a; Loewenstein, 1993). Also, DID individuals commonly have transference/countertransference themes of belief/ disbelief regarding their own symptoms and trauma histories and evoke similar polarization in treatment providers, inpatient psychiatric hospital staff, and the culture at large (Kluft, 1994a; Loewenstein, 1993, 2007; Loewenstein \& Wait, 2008).

Factor analytic studies generally have found that DID symptoms are subtle and covert (Kluft, 1991; Spiegel et al., 2011). They are characterized by shifting, overlapping, and interfering states, accompanied by inner voices and much less often by overt switching behaviors (Dell, 2006a). The latter may be associated with more disruption and problems with functioning. In many cases, several states are experienced as simultaneously, adaptively cooperating to manage various life issues and may be experienced as an ongoing co-presence and co-awareness. However, the shifting and overlapping/ interference among states also can give rise to highly discomfiting passive influence (Schneiderian first rankFRS) symptoms including inner voices conferring about the person; "made" emotions, impulses, and actions; thought withdrawal; and unbidden somatic symptoms. (Kluft, 1987a; Laddis \& Dell, 2012; Putnam, 2016; Ross \& Joshi, 1992; Ross et al., 1990). These symptoms frequently give rise to misdiagnosis of DID individuals as psychotic.

The phenomenology of FRS in psychosis is different from that in DID (Loewenstein, 1991a). Unless there is an intercurrent psychotic process, the DID individual rarely has delusional explanations for FRS, nor report the FRS of thought broadcasting, audible thoughts, and delusional perception (Kluft, 1987a; Laddis \& Dell, 2012; Nordgaard, Arnfred, Handest, \& Parnas, 2008; Ross \& Joshi, 1992). Also, a number of studies link childhood trauma, dissociation, and/or high hypnotizability to the experience of voice hearing and multimodal hallucinosis (Berry, Varese, \& Bucci, 2017; Longden, Madill, \& Waterman, 2012; Longden, House, \& Waterman, 2016; Naish, 2013; Pilton et al., 2015; Whitfield, Dube, Felitti, \& Anda, 2005). Thus, in both clinical and forensic assessments, tracking the phenomenology of FRS and hallucinations can help differentiate DID from psychosis, an important issue in the forensic assessment of CTS and NGRI/NCR.

Kluft (2005) has described the "dissociative surface" as self states that are structured to handle everyday life and to interact with "outside" people, among other functions. He cautions that attending only to the dissociative surface impedes adequate evaluation and understanding of the behavior of DID individuals, many of whom experience behavioral control as emanating from states that remain covert or as a kind of summation of self state "vectors" (Laddis \& Dell, 2012). In many cases, the surface self states profess confusion, puzzlement, fear, and shame about experiencing unbidden —often highly ego-dystonic - thoughts, emotions, urges, body sensations, and behaviors. Typically, surface self states describe varying degrees of dissociative amnesia for important experiences, motivations, and behavior, further compromising coherent, cogent understanding. For example, attending only to the dissociative surface compromises the clinician's ability to assess 
the risk of dangerousness to self or others, since the clinician is most likely not directly interacting with self states controlling these behaviors.

Even in seemingly inexplicable behavior by DID individuals, veteran clinicians can find a "method in the madness," a trauma-dissociation-based, psychologically "logical" way of understanding exactly why, how, and when specific - usually problematic - behaviors occur. Behavior that may seem random and incomprehensible actually has very specific determinants in the inner world of the DID self state system. To better understand DID individuals at the system level, the interviewer should inquire about and track the "passive-influence" experiences that result in lack of control of, or struggle about, thoughts, speech, impulses, or behavior. This also can be tracked by attending to DID "inner voices" that comment, censor, berate, and/or support the self states at the dissociative surface. In some cases, the DID individual will deny "hearing voices" but will acknowledge experiencing uncontrollable, seemingly independent trains of thought expressing ideas quite different from what the surface believes, or in conflict with one another. One patient described this as "free-lance thoughts" (Loewenstein, 1991a).

One may attempt to evaluate, at a given point in time, the totality of the subjective experiences of individual self states, the dynamics of the self-state system, and the level of broad psychological patterns unique to the individual. Comments directed to "all" self states, "the whole mind," etc. are meant to be implicitly integrative and to assert that the DID individual, notwithstanding a subjective experience of self-division, is a single human being, with only one brain, one mind. In clinical practice, one can accomplish this effectively using a technique called "talking over" to direct queries and comments to non-surface self states, the system of selves, or the "whole mind." Sometimes, it may seem as if the interviewer is doing group or family therapy for a single individual (Loewenstein \& Ross, 1992).

\section{Elaboration of Secondary Characteristics in DID}

Over developmental time, a variety of posttraumatic, social, cultural, and relational experiences may lead to secondary elaboration of the self states' characteristics and ways of presenting themselves to others. However, these elaborations are not central to the conceptualization of DID and can be understood in terms of socio-cultural shaping of DID, including trauma-based psychodynamic factors, postulated by Kluft as central to understanding DID (Kluft, 2006, 2007a). The symptoms and clinical presentation of all psychiatric disorders are shaped by socio-cultural factors (Lewis-Fernandez, Guarnaccia, \& Ruiz, 2009; Ryder et al., 2008). For example, nineteenth century schizophrenic individuals did not have delusions of being controlled by weather satellites.
This conceptualization helps make sense of the inclusion of a pathological possession form of DID in DSM-5. In cultures where possession is an accepted experience, for individuals with the pathological possession form of DID, the self states take the form of "possessing entities" that are not congruent with cultural norms (Dorahy et al., 2014; Loewenstein et al., 2017; Spiegel et al., 2011). Individuals with the pathological possession form of DID may have higher rates of childhood and/or adult trauma, compared with others in their culture (Cardena, Van Duijil, Weiner, \& Terhune, 2009; Schaffler, Cardena, Reijman, \& Haluza, 2015; Van Duijl et al., 2010).

In other cultures, the experience of possession in DID is a part of the presentation of non-possession-form DID (Bowman, 1993; Ross, Schroeder, \& Ness, 2013; Sar, Alioglu, Akyuz, \& Karabulut, 2014). Some clinicians even believe there is a differential diagnosis between DID and literal possession (Allison \& Schwartz, 1999). Exorcism rites have been performed on DID individuals, usually accompanied by marked clinical deterioration and phobia of subsequent treatment, as well as spiritual damage (Bowman, 1993). Finally, a sub-group of DID individuals experience some self states as so ego-alien that they describe feeling possessed (Spiegel et al., 2011).

DID experts view the external manifestations of separateness of self states including names, stated gender, voice tone, accent, clothing, hairstyle, varying access to skills and knowledge, type of dissociative amnesia, habits (smoker, non-smoker), etc. as secondary and non-essential to the diagnosis and treatment of DID (Loewenstein, 2018), except to the extent that these secondary characteristics are of psychodynamic importance (Loewenstein, 2018; Loewenstein et al., 2017; Kluft, 2006, 2007a). From a psychodynamic perspective, the separateness and distinctness of self states can be viewed as epiphenomena of structured dissociative defenses (Armstrong, 1994, 2001; Kluft, 1988, 1991). These can even vary considerably over the life span, depending in part on stresses the individual may face (Kluft, 1985b; Maaranen et al., 2008). The consensus among DID experts is that less than 5\% of DID individuals exhibit the starkly different presentations and behaviors among self states that are the popular stereotype for DID (International Society for the Study of Dissociation et al., 2011). A minority of DID individuals display subtler yet consequential presentational differences among states, similar to what Wilbur reported in the book Sybil (Schreiber, 1976) (but more exaggerated in the television and movie versions). Consistent with better overall adaptation and functioning, most individuals with DID do not create or display major disparities in manifest presentation between self states, even when states shift, switch, or are experienced through overlap/ interference phenomena (Kluft, 2006; Loewenstein, 2018).

The DBS conceptualization helps account for multifarious, often seemingly incomprehensible, illogical, even bizarre or "psychotic" self state representations, e.g., child, adult, 
adolescent, elderly, ageless, traumatized, not traumatized, as well as animal, demonic, deity, fantasy character, body part ("the arm said"), chimerical beast, planets, stars, emotions, nameless, ageless, ad infinitum. Similarly, it helps make sense of apparently "impossibly" large numbers of self states. The DID mind is not a "shattered mirror" with a finite number of pieces; it can represent itself in infinite ways. Kluft (1985b) cites a large number of factors that affect secondary structuring of the self states. Most importantly, these include developmental-trauma-based factors, e.g., a young sexually abused girl develops a "boy" self state, with the futilely selfprotective idea that, "if I were a boy, this wouldn't be happening to me" (Kluft, 2006).

Kluft (2006, 2007a) describes the trauma-based psychodynamic factors that, as in the example above, are the most salient ways of understanding self states psychotherapeutically. Other factors include each parent literally treating the person as if he/she was the opposite gender, calling the person by different names, and dressing the person in different gendered clothing. Self states may have relationally trauma-based functions: states that relate only to an abusive parent during incest and others that relate to the parent in everyday contexts (Kluft, 1991). Self states may be subjectively structured to manage a variety of real-world functions: school, work, relationships, parenthood, etc. Other factors can include normal developmental processes like imaginary companionship and childhood fantasy play; personified identification/introjection of people in the child's life; highly variable cultural factors like books, movies, the internet; religious and spiritual experiences; and poorly conducted psychotherapy (Fine, 1989; Kluft, 1985a, 1985b, 1989a; Silberg, 2013).

Also, studies of children with DID show that, in general, they have fewer, simpler and less-subjectively or presentationally_elaborated self states (Silberg, 2013; Silberg \& Dallam, 2009). These are primarily experienced intrapsychically, as autonomous imaginary companions that affect the individual by voices and passive influence, and less by state shifting (Kluft, 1991; Putnam et al., 1996; Putnam, 1997; Trujillo, Lewis, Yeager, \& Gidlow, 1996). With the onset of adolescence, in many cases, the self states seem to "separate and individuate," with progression to the adult form of DID (Putnam et al., 1996).

The DBS model assists with another reification problem: the developmentally improbable notion that there is a "real" person, and his/her "alters" that have "split off" from a "core" person or personality. This conceptualization is problematic even if the DID individual reports experiencing him/herself in this way. For example, inexperienced or naïve clinicians often accept this inherently reified literalism, as if the nominal self state was a head of household with visitors: the "host" self state. The latter is a term of art that designates these types of states and has little evidence base (Loewenstein, Hamilton, Alagna, Reid, \& deVries, 1987). The term "host" connotes that there is a real person and that all other entities are secondary (see Yalom (1989) for an example of this error). An additional term of art, the "typical host" refers to the classic characteristics of this type of state: confused, overwhelmed, depressed, somatizing, rigidly and ineffectually controlling, beset with dissociative amnesia, and wanting to "get rid of" all the other self states, with the latter viewing the "host" as either shamefully contemptible or pitiable, but needing support (Kluft, 2006; Putnam, 1989).

Some DID individuals come to view their overarching identity as contingent upon having the disorder and being a trauma survivor. This is commonly associated with significant narcissistic investment in "being" DID and in displaying complex secondary elaboration of the separateness of the self states (Chase, 1987; Kluft, 1988, 1991). DID experts view this as predictive of much poorer treatment outcomes (Brand, Loewenstein, \& Lanius, 2014; International Society for the Study of Dissociation et al., 2011; Kluft, 1994b). The overt presentational differences among self states in some DID individuals can be so compelling as to make it difficult, even for experienced assessors, to hold onto the understanding that the individual is a single human being with a single over-all mind and a single personality. Unfortunately, it is these DID individuals who usually appear in the media and who actually are unwittingly being exploited and victimized by the circus-like, freak-show atmosphere of popular media portrayals of DID (International Society for the Study of Dissociation et al., 2011). On the other hand, clinical and epidemiological data suggest that the majority of individuals with DID do not, or only subtly manifest, overt DID symptoms except at times of stress and life crisis (Kluft, 1991; Maaranen et al., 2008).

Most clinicians and forensic practitioners, as well as the public, receive training in DID from the media (Loewenstein, 2018). For many practitioners, the "searching image" for DID is based on these fictional, non-fictional, and popular autobiographical portrayals. Compounding the problem, there is a dearth of training altogether in most mental health fields concerning trauma-related disorders, especially complex posttraumatic and dissociative disorders that are associated with earlier and cumulative trauma (Brand et al., 2018; Brand, Schielke, et al., 2019; Loewenstein, 2018; Stein et al., 2013; Wilgus, Packer, Lile-King, Miller-Perrin, $\&$ Brand, 2015). This is particularly unfortunate since epidemiological studies show that traumatic experiences are ubiquitous in the general population, with a $6.8 \%$ lifetime prevalence for PTSD, making it more common than schizophrenia or bipolar disorder (Green et al., 2010; Kessler, 2000; Kessler, Sonnega, Bromet, Hughes, \& Nelson, 1995; Kessler et al., 2005; McLaughlin et al., 2010). Across international general population studies, the lifetime prevalence of all DD is conservatively estimated as about $10 \%$, with a $1-3.5 \%$ lifetime prevalence of DID (Loewenstein, 2018). DID patients spend on average $5-12.5$ years in mental health treatment before 
correct diagnosis (Spiegel et al., 2011). Skeptics wonder how can this be? They have "never" seen a case of DID. DID is hiding in plain sight. The dissociative symptoms are embedded in the co-morbidities and the poly-symptomatic ACE outcomes: subtle, covert, and minimized (Dell, 2009; Loewenstein, 1991a).

\section{The DBS Model and Other Disorders}

Putnam (2016) describes how behavioral state theory can help one understand a variety of psychiatric disorders as "statechange" disorders. For example, he describes the profound shifts in behavioral states he observed when he studied rapid cycling bipolar patients at the National Institutes of Mental Health. As in DID, these patients showed a "switch process," where marked changes in mood, activation level, motor activity, interpersonal relatedness, and cognition, as well as other variables, would rapidly shift when changing from profound depression to euthymia, to mania, and back again. Other psychiatric disorders can be conceptualized more broadly as statechange disorders: panic disorder, generalized anxiety disorder, periodic catatonia, brief psychotic disorder, PTSD, ASD, substance use disorders, gambling disorder, bulimia nervosa, binge eating disorder, delirium, intermittent explosive disorder, oppositional defiant disorder, some parasomnias, DD such as dissociative amnesia and depersonalization/derealization disorder, and some forms of conversion disorder, e.g., psychogenic non-epileptic seizures. Disorders such as attention-deficit hyperactivity disorder (ADHD) can have aspects of state-change symptoms, e.g., ADHD children can alternate from disorganized, hyperactive states to hyperfocused states, e.g., when playing video games. In anorexia nervosa, loss of weight engenders a food-deprived, starvation state which dominates all aspects of the person's consciousness. Classically, there are models for markedly different behavioral states during the progression of symptoms during the onset of first-episode psychosis, although more recent studies have found limited evidence for this model (Hafner et al., 2003). Some chronic schizophrenics may have rapid, stress-related onset of worsening in psychotic symptoms that can be understood in the DBS framework.

Putnam (2016) hypothesizes that understanding discrete behavioral states could be a testable, organizing principle in the empirical study of mind/brain/body/behavior across many research paradigms and may allow for translational research from organismal to molecular levels of analysis (Putnam, 2016). For example, DBS theory also provides a framework for studying "normal" altered states: meditation, peak experiences, sexual experiences, epiphanies and spiritual experiences, ecstatic religious states, "secret lives," and many others. DBS theory is relevant to neurobiological studies such as those of sleep and its stages; waking brain states, such as the default mode network versus other brain network states; very rapid shifts in brain microstates; and in the study of the cellular underpinnings of sleep stages at the molecular, cellular, and genetic levels.

\section{Why Not Structural Dissociation Theory Instead of DBS Theory?}

Onno van der Hart, Ellert Nijenhuis, and Kathy Steele developed what they present as a comprehensive theory of dissociation: Structural Dissociation Theory (SDT) (van der Hart, Nijenhuis, \& Steele, 2006; Steele, van der Hart, \& Nijehhuis, 2009). SDT postulates an overarching theory of dissociation and attempts to account for a range of posttraumatic disorders, conceptualized as based on "structural dissociation of the personality." These include all dissociative disorders (DD), acute stress disorder (ASD), "simple" PTSD, complex PTSD (CPTSD), "trauma-related" BPD, disorders of extreme stress not otherwise specified (DESNOS) (Herman, 1993), ICD-10 "simple and complex" dissociative disorders of movement and sensation (DDMS) (World Health Organization, 1992), and DSM-5 conversion disorder (CD), also known as "functional neurological symptom disorder" (American Psychiatric Association, 2013; van der Hart et al., 2006). SDT is probably the most widely known theory of dissociation and is particularly prominent in Europe.

SDT is largely based on the conceptual framework developed by Pierre Janet (1859-1947) for understanding psychological functions, as well as his theories about phenomenology and treatment of dissociation and hysteria (Janet, 1887, 1907, 1924; van der Hart \& Friedman, 1989). However, consistent with DBS theory, van der Hart et al. report that " $[\mathrm{t}]$ he personality as a system can be understood as being comprised of various psychobiological states or subsystems that function in a cohesive and coordinated manner" (van der Hart et al., 2006) (page 2 , italics added).

Although, at times, SDT theorists use metaphors for psychobiological processes, they primarily describe the mind, behavior, personality, and dissociation using metaphors for structure. In the view of the author, the proponents of SDT appear unaware of the implications of their almost exclusive use of physicalist metaphors in their terminology - and, indeed, that these are metaphors, ones that particularly may lead to problematic reification of self-states (personal communication, Onno van der Hart, November 10, 2002, Baltimore, MD). Some psychoanalytic authors make a similar critique of the term "splitting" in the psychoanalytic literature as likely to lead to concrete, physicalist reification of mental processes (Lustman, 1977). In psychological epistemology, theorists need to be aware of the distance of their conceptualizations from empirical observation and scientific data, and that their terminology for hypothesized mental functions will invariably involve metaphor to convey meaning. Theorists need to be cognizant and explicit in their use of metaphors and, 
accordingly, be aware of their/our limitations conceptualizing abstractions like "the mind," "personality," "dissociation," etc., and that different metaphors have varying connotations and denotations.

In SDT, "division in personality" is described by the term "dissociative parts of the personality"- a problematic term since a "personality" is not physical or mechanical, and, as an abstraction, cannot have "parts." SDT follows the language of Charles Samuel Myers (Myers, 1915, 1916, 1940) who described severely traumatized soldiers in World War I as alternating between an Apparently Normal [Part of the] Personality (ANP), and an Emotional [Part of] the Personality (EP) (the term "Part of the" was added by van der Hart et al. (2006), p. 5). The hypothesized ANP is constricted and avoidant, unaware of traumatic memories, externally focused on daily life, and phobic of internal experiences. The EP is filled with the pain and distress of unintegrated, unprocessed traumatic memory.

In this theory, ASD, "simple types" of PTSD, DD, and disorders of movement and sensation result from a "single" EP and ANP. "Secondary structural dissociation" with one ANP and more than one EP results in CPTSD, DESNOS, DSM-IV-TR (American Psychiatric Association, 2000) DDNOS, trauma-related BPD, and complex forms DDMS. "Tertiary structural dissociation" results in the development of DID, often with several ANPs and EPs that may be more "autonomous," with the elaboration of secondary features of DID such as differing names, clothing, physical features, etc.

A major issue with SDT is how to operationalize terms like "apparently," "normal," "emotional," and "personality" for research purposes or for rigorous clinical work. For example, there is no overarching, unified scientific construct for "normal," let alone "apparently normal." Individuals with nondevelopmentally based PTSD can struggle with significant complexity of symptoms and difficulties in life, as well as co-morbidities. In the author's view, the connotations that some disorders are "simple" and others "complex" are inherently problematic and may have the unintended consequence of individuals with "simple" disorders not being viewed as seriously as those with "complex" psychopathology.

SDT proponents $d o$ cite DBS theory as essential in young children for the development of dissociation and attachment pathology, particularly type $\mathrm{D}$, or disorganized attachment (Steele et al., 2009). As described by DBS theory, this type of attachment pathology is particularly associated with dissociation in the mothers, and development of symptomatic levels of dissociation in their children when they reach adolescence (Byun, Brumariu, \& Lyons-Ruth, 2016; Farina, Liotti, \& Imperatori, 2019; Liotti, 2009; Lyons-Ruth, Dutra, Schuder, \& Bianchi, 2006; Ogawa, Sroufe, Weinfeld, Carslson, \& Egeland, 1997). However, having posited developmental aspects of dissociation in DBS terms, SDT theorists quickly move back to using the oversimplified language of
ANPs and EPs when describing what occurs as children develop. For example, they conceptualize a shifting of ANPs and EPs to explain the complex, interactional behavior of mothers and children with type-D attachment when studied in standardized attachment paradigms, e.g., the Strange Situation, as well as longitudinally (Carlson, 1998; LyonsRuth, 2008).

The SDT model appears to be based on reasoning backwards from observations of adult DID and other severely dissociative complex trauma patients. In contrast, the DBS model is grounded in observational, prospective and retrospective research on infant and child development, on children with attachment pathology, and on traumatized children and adolescents, as well as on a multi-generational, longitudinal case-control studies of sexually abused girls, among others (De Bellis \& Putnam, 1994; Lewis \& Yeager, 1996; Putnam, 1997, 2006, 2016; Silberg, 2000, 2004, 2013; Silberg \& Dallam, 2009; Trickett et al., 2011).

SDT proponents insist that their theory encompasses all forms of ASD and PTSD, not just DD, and that ASD and PTSD are fundamentally "dissociative." However, comprehensive meta-analyses of PTSD and dissociation, along with rigorous statistical modeling, are consistent with dissociation as either a subtype or a component of PTSD, rather than dissociation as underlying all forms of PTSD (Dalenberg \& Carlson, 2012; Dalenberg, Glaser, \& Alhassoon, 2012; Carlson, Dalenberg, \& McDade-Montez, 2012). ${ }^{2}$

At the level of clinical theory, SDT can be helpful as a heuristic for aspects of the diagnosis and treatment of posttraumatic and dissociative disorders, notwithstanding the problematic vocabulary (Boon, Steele, \& van der Hart, 2011). Like other models of treatment for complex trauma and dissociative disorders, SDT posits a tripartite treatment framework that prioritizes safety and stability, and affect regulation and symptom management skills in stage 1 ; more intensive work on traumatic memories in stage 2 ; and focus on integration into life/fusion-integration of self states in stage 3 , with additional post-integration therapy continuing in an extended stage 3 (Boon et al., 2011; Brand, McNary, et al., 2012; Herman, 2015; International Society for the Study of Dissociation et al., 2011; Kluft \& Loewenstein, 2007; van der Hart et al., 2006). Despite their stance as Janetian theorists, SDT proponents do include some ideas from psychodynamic theory such as the therapeutic alliance, treatment frame, etc. (van der Hart et al., 2006). However, these are not integrated into SDT itself, losing a rich body of psychodynamic clinical theory. The author has argued that treatment of DID - as well as of DA-is best served by a synthesis of Janetian and

\footnotetext{
${ }^{2}$ In the DSM-5 diagnostic criteria for ASD and PTSD, flashbacks are explicitly described as "dissociative." In this sense, all forms of ASD and PTSD are "dissociative." However, SDT conceptualizes these disorders in terms of a specific psychological mechanism postulated to underlie these disorders: the existence of ANPs and EPs.
} 
Freudian notions (Loewenstein, 2014; Loewenstein et al., 2017; Loewenstein \& Ross, 1992; Loewenstein \& Welzant, 2010). SDT has been useful in neurobiological studies of DID, where traumatic identity states (TIS) have been compared with neutral identity states (NIS - presumably ANPs), as well as simulating controls on responses to personal trauma scripts (Reinders et al., 2016). On PET and fMRI scanning, as well as autonomic measures, TIS respond to trauma scripts similarly to non-dissociative PTSD subjects, while NIS respond as if the scripts represent non-autobiographical memory, and appear more like subjects with dissociative subtype of PTSD (Reinders et al., 2014).

Finally, proponents of SDT view SDT as a "general theory" of all dissociative and posttraumatic disorders, as well as of conversion disorder. It is a top-down theory. Proponents of SDT posit that virtually all trauma-related psychopathology should be conceptualized according to their model. They appear to have a hegemonic view of their theory: that it should be uncritically adopted by the DD field, as well as its terminology, e.g., "dissociative parts of the personality," "ANP," "EP," etc. They appear unaware of potential critiques of the theory and are discomfited when told that not everyone agrees with SDT, its terminology, their lack of acceptance of PTSDDS and positing ASD and PTSD as fundamentally dissociative, etc. (personal communication, Ellert Nijenhuis, Berlin, Germany, March 31, 2012). Often, SDT supporters seem more concerned with adherence to the theory than in developing research methodology that could empirically test it. For example, Nijenhuis, in an attempt to counter the notion of PTSD-DS (2014), and unlike the work of Dalenberg and Carlson (2012) and Carlson et al. (2012), primarily gives theoretical and anecdotal arguments that ASD and PTSD are fundamentally "dissociative." He does not provide metaanalytic data and cites limited empirical data in support of his view.

In the author's view, the major problem with SDT is that it oversimplifies the complex experiences of traumatized individuals at a variety of levels: psychobiological, developmental, attachment-based, intrapsychic, cognitive, intellectual, emotional, interpersonal, relational, socio-cultural, etc. The major SDT proponents appear more concerned to fit all things posttraumatic and dissociative into their theory, rather than developing research to test it.

\section{Next Steps: Doris Neely and the Legal System}

Ms. Neely arrived for her arraignment Monday morning accompanied by her husband and a prominent defense attorney. During the hearing, she began to behave in bizarre ways. She cried out, put her head down on the defense table, moaned, spoke in a child-like voice, placed her hands on her temples, rocked back and forth, and talked to herself. She was oblivious to requests from the hearing officer to pay attention to the proceedings. After a recess, she returned to the courtroom looking around blankly. Her defense attorney reported to the court that the symptoms of his client's DID made it impossible, even with her husband's assistance, for her to talk with him rationally about the charges and requirements for her defense, and to respond appropriately in court. He requested a mental health evaluation. With the concurrence of a court mental health consultant, the court ordered that Ms. Neely be remanded for psychiatric evaluation at the state hospital forensic unit, where she was immediately transferred.

Here, she received psychiatric, psychological, neurological and physical therapy assessments, as well as 24hour observation by trained forensic hospital staff.

Ms. Neely was difficult to manage on the state hospital unit. Without her crutches, she was primarily wheelchair bound and sometimes required staff to roll her where she needed to go. On several occasions, she suddenly bolted out of her wheelchair in an apparent dissociative fugue state, seemingly trying to escape. She ran down the hall, slamming walls and trying to break the security windows by smashing them with her fists. Ms. Neely also engaged in a variety of self-destructive behaviors such as head-banging, arm-scratching and hitting her temples with her fists. She denied recalling these events but later would describe them in detail in the context of blaming staff for what she considered their poor responses.

At times, she denied recall for both mundane and important events. Moments later, she would cogently describe in detail what she had just denied remembering. She denied recollection of clinical interviews, tests, interactions with staff, and especially her own actions that staff found dangerous or problematic. Ms. Neely did recall in detail, however, everything that displeased her. She complained bitterly about the staff's supposed lack of attention to her needs and their failure to understand her various self states and that it was the self states, not "Doris," who caused problematic behaviors.

The professional staff had difficulty engaging Ms. Neely for clinical and forensic interviews. When she presented as "Doris," she was pleasant and bland. Doris denied recalling her past history, the crimes for which she was accused, and behavior witnessed moments before. In the Doris mode, she claimed that several years before, she had suffered a severe head injury 
resulting in a "3-day coma" and loss of memory for her entire life history, compromising her ability to now give a coherent history.

Initially, Ms. Neely refused to give permission for access to prior psychiatric and medical records, stating, "it's just going to be used against me." However, her attorney insisted that she do so, including giving permission to interview Ms. Brown, her most recent psychotherapist. Reluctantly, Ms. Neely complied.

\section{Past, Personal, Legal, and Psychiatric History}

The following narrative describes the most consistent version of Ms. Neely's past history and is based on her psychiatric records, the forensic records and assessments, and my interviews with her. I obtained collateral information from Ms. Neely's husband, son, and attorney, and through interviews with a number of Ms. Neely's prior psychotherapy and psychiatric treatment providers, including Ms. Brown.

Ms. Neely reports being the second of four children born into an intact family living in a semi-rural area in the southwest. She reports a family history of multigenerational alcoholism, mood disorders, and sadistic maltreatment of children. She describes being raised as a girl called "Doris" by her mother and as a boy called "Sonny" by her father. She states that each parent would dress her in clothes consistent with the desired gender. She describes violent, sadistic sexual abuse involving bondage; physical maltreatment including burning with fire and caustic substances; confinement abuse, such as being locked in a garbage can; and severe emotional abuse and humiliation, primarily perpetrated by her father and her paternal grandfather. Further, she reports her father carried out sexual assaults involving the family dogs. She admits to poisoning the dogs in an attempt to stop this form of abuse. She described her mother as noticeably favoring the other children, a source of devastation to Ms. Neely.

Around age 18, Ms. Neely left the family to live in another city, where she met Mr. Neely, now her husband of over 30 years. She reports experiencing several episodes of "date rape" before she met him. At one point, when Mr. Neely seemed to be distancing himself from their relationship, he discovered the wiring of his car engine had been torn out. Later, when they had reconciled and finally married, Ms. Neely admitted doing so because of anger and jealously at his withdrawal. Early in the marriage, Ms. Neely drove away from a gas
Table 2 Formal legal history

\begin{tabular}{|c|c|c|c|}
\hline $\begin{array}{l}\text { Date/ } \\
\text { place }\end{array}$ & Charges & Disposition & Comments \\
\hline 1975 & $\begin{array}{l}\text { Petit larceny } \\
\text { Assault and } \\
\text { battery }\end{array}$ & $\begin{array}{l}\text { No disposition } \\
\text { recorded }\end{array}$ & Gas drive off \\
\hline 1992 & $\begin{array}{l}\text { Threatening to } \\
\text { injure } \\
\text { individuals } \\
\text { with explosive }\end{array}$ & $\begin{array}{l}\text { Mandated to } \\
\text { therapy }\end{array}$ & Taco Bell threat \\
\hline 1998 & Petit larceny & $\begin{array}{l}\text { Covered by case } \\
\text { below ... }\end{array}$ & \\
\hline 1998 & $\begin{array}{l}\text { Aggravated } \\
\text { harassment 2nd } \\
\text { class A } \\
\text { misdemeanor }\end{array}$ & $\begin{array}{l}\text { Convicted on plea } \\
\text { of guilty; } \\
\text { probation } 3 \text { years } \\
\text { beginning } 1998\end{array}$ & $\begin{array}{r}\text { Stalking, harassment of } \\
\text { prior therapist; order } \\
\text { of protection granted }\end{array}$ \\
\hline 1999 & $\begin{array}{l}\text { Criminal } \\
\text { contempt }\end{array}$ & $\begin{array}{l}\text { Convicted on plea } \\
\text { of guilty; } \\
\text { conditional } \\
\text { discharge } 1999\end{array}$ & $\begin{array}{l}\text { Calling therapist, } \\
\text { driving by her } \\
\text { house, in violation } \\
\text { of order of } \\
\text { protection }\end{array}$ \\
\hline 2007 & $\begin{array}{l}\text { Shoplifting } \\
\text { incident, } \\
\text { charged with } \\
\text { larceny }\end{array}$ & $\begin{array}{l}\text { Pled nolo and paid } \\
\text { fine-District } \\
\text { Court }\end{array}$ & $\begin{array}{l}\text { Therapist wrote a letter } \\
\text { to court on her } \\
\text { behalf }\end{array}$ \\
\hline 2007 & $\begin{array}{l}\text { Arson, 1st degree, } \\
\text { attempted } \\
\text { burglary, } \\
\text { occupied } \\
\text { dwelling }\end{array}$ & See narrative & Witnessed \\
\hline 2007 & $\begin{array}{l}\text { Arson, 1st degree } \\
\text { burglary }\end{array}$ & See narrative & $\begin{array}{l}\text { Former therapist's } \\
\text { home }\end{array}$ \\
\hline
\end{tabular}

station without paying, leading to her first known arrest. [See Table 2-Ms. Neely's known legal history]

Mr. Neely's work required frequent moves. Ms. Neely was brought to psychiatric attention for the first time in her mid-twenties, now the mother of two small sons. She was hospitalized, and a diagnosis of possible multiple personality disorder (MPD) ${ }^{3}$ was confirmed. Mr. Neely reports he was nonplussed by this diagnosis, yet found it helped explain his wife's perplexing shifts in behavior, memory problems and variable access to learned skills.

Over several years, Ms. Neely was treated as an outpatient and also had several long hospitalizations. The initial MPD/DID therapist described a similar roster of self states to those reported by all subsequent providers and by her family. Across all assessments, Ms. Neely consistently reported the same childhood trauma history.

\footnotetext{
${ }^{3}$ Multiple personality disorder (MPD) was changed to dissociative identity disorder (DID), starting with DSM-IV (1994).
} 
Mr. Neely and their grown son report having interacted with Ms. Neely's self states over many years. The family and the clinicians all describe "Doris" as pleasant and engaging, but with multiple somatic symptoms-headaches, leg and arm pain, difficulty walking, gastrointestinal problems, and pelvic pain - and manifesting dense amnesia for many aspects of her past and current experience. They describe several male and female child self states, including "Sonny," "Jimmy," "Dorrie," and "Mary Lou," and a thumbsucking infant state named "Baby." There is a state based on her father and carrying his name. Other older self states include "Anne West," described as competent, business-like, and functional at work and as keeping order in finances, household tasks, childcare, and cooking at home, and "Jeffrey," in which state Ms. Neely can display anger and at times is threatening towards others. Jeffrey would emerge with a marked change in posture and facial expression and with a deeper voice. Ms. Neely reports additional rage-filled states called "Red 1," experienced as violently suicidal, and "Red 2," experienced as angry and potentially violent.

The Neely family moved several more times, at one point spending several years in a Southern city. There, Ms. Neely entered psychotherapy with a therapist who reportedly insisted repeatedly that Ms. Neely had been subjected to "Satanic Ritual Abuse (SRA)" and had become "possessed by demons." The therapist and other members of her church, and even other DID patients, were said by both Mr. and Ms. Neely to have engaged in repeated, attempted exorcism sessions - sometimes lasting up to 8 hours - to remove Ms. Neely's alleged demons. In particular, the self state Jeffrey, because of the radically different male presentation, was reportedly deemed a Satanic manifestation. In one of my interviews, when Ms. Neely shifted to the Jeffrey self state, she reported that, "[The therapist] kept calling me Satan or Lucifer and trying to get me out of there. I kept telling her that I was Jeffrey, not Satan, and I wasn't going anywhere!" At other times, this therapist was said to have "nursed Ms. Neely with a baby bottle," encouraging Ms. Neely to call her "Mommy." According to Mr. Neely, the therapist also attempted to concretely "repair" Ms. Neely's reports of emotional cruelty and abandonment by her mother, especially around church functions, where Ms. Neely felt her mother ignored her compared with her siblings.

Mr. and Ms. Neely report that this "treatment" led to almost weekly hospitalizations due to self-destructive and suicidal behavior, particularly after the attempted exorcisms. The therapist would continue the therapy/ exorcism sessions with Ms. Neely in restraints on an inpatient unit. Despite repeated psychological pressure to say otherwise, Ms. Neely reports continuing to tell the therapist that she was never "ritually abused," nor was the Jeffrey self state a demonic intruder. In my interviews, Ms. Neely specifically denied any history of organized ("ritual") abuse, and no other clinician noted this type of history, either in the medical record or in my interviews of Ms. Neely's prior treatment providers.

The Neely family relocated to another state. Apparently, Ms. Neely was referred to her next therapist as a courtordered disposition for having phoned in a bomb threat to the manager of a restaurant where she had been working, although this was not a focus of therapy, and no clear details of this event are present in the past records. The new therapist attempted to initiate a board complaint against the prior therapist for treatment that fell below the standard of care, but the state board refused to take it, responding that there was no evidence to support Ms. Neely's accounts. To be sure, when I contacted Ms. Neely's various prior therapists, I learned Ms. Neely had not always been an accurate reporter of what occurred with these clinicians. However, Mr. Neely confirmed witnessing the exorcisms, the hospitalizations, the activities with the therapist at church, etc.

This new therapy was tumultuous, with Ms. Neely engaging in repeated self-destructive behavior and threats of suicide. She experienced severe PTSD flashbacks and intrusive symptoms, as well as dissociative fugues. The therapist attempted to do "progressive therapy," to help Ms. Neely's self states experience a subjective age progression or "growing up." Thus, the subjective baby self state no longer "needed the bottle" and other subjectively younger states were encouraged to become less regressed and discouraged from engaging with the therapist as "Mommy." Angry and potentially violent states entered into therapy. The Jeffrey state emerged and violently threw the therapist's bookcase to the floor. After this event, the therapist no longer felt safe being alone with Ms. Neely and insisted that Mr. Neely either sit in on therapy sessions or remain close by in the waiting room as a condition of continuing treatment. In the author's clinical experience, when there has been prior therapist misconduct, the DID patient may find ways, even by symptomatic behavior, to not be alone with the therapist in the office, or at least to have someone nearby, even provoking repeated psychiatric hospitalizations so others "can keep an eye on" the subsequent therapist (Kluft, 1989b).

The Neely family moved again repeatedly. Over several years, Ms. Neely was treated by several therapists, one 
of whom may have taken out an order of protection against her. No records have been found for these treatments, and neither Mr. nor Ms. Neely are forthcoming about them. Reportedly, during this time, Ms. Neely fell at her place of employment and developed severe back pain, for which, eventually, a lumbar fusion was performed. Ms. Neely was awarded disability on the basis of her back injury. She began to use assistive devices for reported lower extremity weakness, pain, and difficulty ambulating. However, Mr. Neely reports that, in the Jeffrey state, Ms. Neely ambulates without difficulty and helps him with home repairs, even climbing onto and walking on the roof.

After a subsequent move, and in a new therapy, Ms. Neely began to report to her therapist that she had set a number of fires in the local area, including a widely publicized major arson at a large mall. However, she was not arrested for any of these. On interview, the therapist averred that Mr. Neely knew his wife had set the fires, but was mostly concerned with protecting her. The treatment was extremely stormy, with multiple hospitalizations. Ms. Neely engaged in severe self-destructive behavior including cutting and burning herself, pulling out her toenails, and dousing herself with gasoline. Again, the therapist insisted, as a condition of treatment, that Mr. Neely sit in on sessions or remain in the waiting room. The therapist had to call 911 several times when Ms. Neely was engaging in wildly self-destructive behavior in the office, office bathroom, or waiting room, with the therapist and Mr. Neely having to physically restrain her. Ms. Neely reportedly informed the therapist that she could escape from any physical restraint and elope from any hospital, and she did so. Indeed, during one elopement, Ms. Neely entered her therapist's garage and vandalized the therapist's car, leading to a variety of criminal charges. The charges ultimately were pled down to larceny. [See Table 2]. The therapist terminated the treatment.

After the termination, Ms. Neely was said to have engaged in stalking the therapist. Eventually, the therapist took out an order of protection (restraining order) against Ms. Neely [see Table 2]. Ms. Neely repeatedly violated this order, claiming that some self states "didn't know" that treatment had ended. Finally, charged with violating the order of protection, Ms. Neely, her husband, and attorneys for all parties met in the judge's chambers. Ms. Neely agreed to maintain the boundaries of the order of protection. Ms. Neely maintained complete composure during all the legal proceedings related to this matter, and no longer harassed her prior therapist.
During this time, Ms. Neely also had unsuccessful courses of inpatient specialty trauma disorders treatment for DID at two different, nationally known programs. In both settings, she refused to engage with the treatment program in any meaningful way. She was disruptive, damaged property, and was alternatingly childish and needy, or angry, demanding and demeaning towards the staff. She tried to elope, brought in a large stash of medication concealed in a stuffed animal, and repeatedly insisted on being returned to outpatient care.

The family moved again. Ms. Neely reportedly was employed, liked her home, and had a period of apparent relative stability. During this period, Ms. Neely had another minor slip and fall accident that resulted in a mild concussion. Later, she claimed that she experienced a "3-day" coma with subsequent complete memory loss for all aspects of her personal identity and life history. She frequently cited this event as accounting for her later memory problems. Contemporaneous medical records from the emergency department, including a neurological consultation, described normal neurological, laboratory and imaging studies. Later comprehensive neurological studies, including an EEG and MRI of the brain, were entirely within normal limits. Despite this, after this event, Ms. Neely underwent three years of specialized therapy for "cognitive retraining." In my interviews of Mr. Neely and the adult son, they both described the time of Ms. Neely's "total" memory loss as a relief and a reprieve. The self states did not manifest, and the continual turmoil associated with DID was quiescent. Ms. Neely did not seek psychiatric or psychological treatment again until the family moved to the current home in an area where Mr. Neely had many relatives nearby.

After this most recent move, Ms. Neely sought treatment from a number of providers. Finally, she was seen in the University Medical Center Outpatient Psychiatry Clinic. Ms. Brown was asked to treat her, as Ms. Brown had experience treating DID patients. Ms. Neely received psychopharmacological treatment at the clinic, as well. According to Ms. Brown, Ms. Neely was very unhappy about this last move. She complained of a more isolated living situation and many more conflicts with her husband than in their prior home. She reported being ostracized by Mr. Neely's relatives.

Treatment was wildly turbulent from the beginning. Ms. Neely exhibited all the problematic behaviors reported by previous providers. She was plethorically self-destructive. Violent, angry self states were prominent. 
Ms. Neely pulled out her toenails, excoriated her skin, banged her head, cut and burned herself, and repeatedly took too many medications.

On the other hand, for periods of time, she would appear to be making progress in therapy. Ms. Brown was able to work with several angry self states, resulting in decreased turmoil in therapy and improved functioning and safety. Ms. Neely achieved better internal communication and cooperation among the self states. There appeared to be a better alliance with the angry, violent states. There were periods of relative symptomatic quiescence. However, when family conflicts increased, Ms. Neely destabilized. She reported to Ms. Brown that she had set multiple fires in the countryside around her home. Then, she recanted, stating that a self state "always took the blame for things," and that someone else had been charged with these crimes. She described killing at least one of the family dogs, because her husband liked a breed Ms. Neely associated with the reported bestial child abuse. Ms. Brown persuaded the family to give away their remaining dogs of this breed, keeping only the small dogs that Ms. Neely did not find triggering.

After safety crises, Ms. Neely would be briefly hospitalized in the university or another local psychiatric unit. Both were short-term units, primarily for crisis stabilization. Shortly after admission, she would claim that she was stable again, and her husband would take her home. In one tempestuous session, Ms. Neely reported being triggered by a dog brought to the clinic by one of the therapists. The self state Dorrie was said to have emerged, and Ms. Neely ran to a window, shattered it, and cut herself bloody with the glass. Then she ran throughout the clinic, disrupting many patients and clinicians. Ms. Brown finally was able to physically restrain her patient. By the time her husband arrived, Ms. Neely had switched to a seemingly competent, grounded, everyday self state and denied responsibility for that behavior or any further dangerousness to self. Over Ms. Brown's objections, Mr. Neely took his wife home. After this event, however, the clinic administration required Mr. Neely to attend therapy with his wife or remain close outside the door as a condition for the clinic to continue her care. Ms. Brown was required to see Ms. Neely in another part of the clinic, away from most of the other patients and staff. Ms. Neely was told that another violent outburst would result in treatment being terminated by the clinic.

The Neely family was re-modeling a home into which they planned to move. At one point, Ms. Neely reported to Ms. Brown that she had been raped by one of the workmen on the site. She became increasingly suicidal, calling Ms. Brown repeatedly in crisis.

Shortly after this, Ms. Neely was arrested and charged with shoplifting clothes in a big-box store. She claimed that she had seen her recent assailant in the store, a terrified child state had urinated in her clothes, and, embarrassed, she stole other clothes that she put on, placing her wet clothes in a bag. She was caught at checkout, and the police were called. At Ms. Neely's request, Ms. Brown wrote a letter to the court explaining the dissociative and posttraumatic factors that Ms. Neely claimed had led to the shoplifting. Ms. Neely did not contest the charge and paid a fine (see Table 2).

After the reported rape, there were more conflicts with her husband. Ms. Brown suggested a couple's therapy session for Ms. Neely to tell her husband about the rape. In the session, Mr. Neely was clearly upset and attempted to comfort his wife by trying to hold her hand, which she rebuffed. She left to go to the restroom, and, ambulating with her crutches and braces, fell in the hall and had difficulty getting up. The husband leaned over to assist his wife, who, apparently experiencing him as a dangerous man, suddenly switched to the Dorrie state and ran through the hall, breaking a window and cutting herself. Ms. Brown reported in my interview with her that, at the time, she secretly felt relieved knowing that Ms. Neely would be terminated from the clinic.

Ms. Neely finally was hospitalized at a large, regional psychiatric center and was told that her treatment with Ms. Brown was over. She underwent an extensive psychiatric, psychological, neurological, orthopedic, and physiatry evaluation. The staff confirmed the DID diagnosis, but no neurological basis could be found for Ms. Neely's reported memory problems, severe back pain, leg pain, and inability to ambulate. There was no medical indication for Ms. Neely to require leg braces, crutches, or any other assistive device. The psychological testing was hard to interpret because Ms. Neely averred that different self states took different tests.

After discharge, although referred to another therapist, Ms. Neely continued to call Ms. Brown, denying that she knew treatment had ended and begged for an appointment. Ms. Neely pleaded to have a termination session, but she was not allowed to return to the clinic. Barraged by Ms. Neely's increasingly desperate pleas, against her better judgment, Ms. Brown reluctantly agreed to hold a termination session at her home. Ms. Neely had seen photos of Ms. Brown's horses on her 
screen saver and asked for the child states to "meet the horsies." The termination meeting was held at Ms. Brown's horse barn, with different self states emerging to say "goodbye." Ms. Brown was very uncomfortable in this situation, especially because Mr. Neely and the Anne self state insisted on "not telling Doris" what had happened, "because she couldn't handle it." As Doris, Ms. Neely continued to call Ms. Brown, expressing confusion at why treatment had ended. She would also call as different states, beseeching to get back into therapy and asking Ms. Brown to be her "friend."

Several months after Ms. Neely's termination session at the barn, Ms. Brown's house and horse barn were vandalized. Among other damages, the garage door was rammed by a vehicle pushing slowly to crumple the door. The police investigated but, according to Ms. Brown, did not pursue the case vigorously. After this event, Ms. Neely left Ms. Brown a voice mail expressing condolences and saying, "You don't think that $I$ had anything to do with it, do you? I loved those horses. I would never hurt you."

\section{Forensic Issues and DID}

The intersection between the diagnosis of DID and the courts has been complex, difficult, and controversial (Brand, Webermann, et al., 2016; Brand et al., 2018; Lewis \& Bard, 1991; Orne et al., 1984; Watkins, 1984). Some forensic experts do not view the disorder as an authentic psychiatric condition (Coons, 1991; Lilienfeld et al., 1999; McHugh, 1995; Merckelbach \& Patihis, 2018).

In civil/administrative litigation, individuals with DID — or purported DID - may be involved as plaintiffs or defendants in a variety of cases where the DID diagnosis is material to the case. These include malpractice litigation; professional licensing board complaints; sexual harassment; therapist misconduct; worker's compensation; disability litigation; fitness for duty evaluations and family law cases involving divorce and child custody evaluations, among others (see below) (Brand, Webermann, et al., 2016; Brand, Schielke, \& Brams, 2017; Brand, Schielke, Brams, et al., 2017; Kluft, 1987c; Simeon \& Loewenstein, 2009). Some individuals with DID are reported to child protection services due to abuse or neglect of their children (Kluft, 1987b).

\section{Psychological Injury and DID}

There are no systematic data about DID in any forensic context: criminal, civil, administrative, disability, etc. As in the criminal setting, comprehensive forensic assessment of DID individuals in civil litigation and administrative contexts requires, to the extent possible, comprehensive assessment of the patient; interview of collateral informants; review of all medical and other pertinent past records, e.g., school records; review of deposition and other testimony of the DID individual and other witnesses; psychological assessment, including specialized assessment for trauma-related dissociation and DD; and medical and functional assessments (American Association of Psychiatry and the Law, 2015). In disability and related evaluations, there may be constraints on materials the assessor can review, and reports may be required of the patient's treating provider (Anfang, Gold, \& Meyer, 2018).

In the author's experience, Ms. Neely is not typical of DID individuals in these kinds of cases. In addition to her involvement in the criminal justice system, she obtained social security disability by claiming a back injury in a "slip-and-fall" case, where later examinations could discern no objective pathology to account for her complaints of pain and limitations of movement. She received years of cognitive retraining for an episode of generalized dissociative amnesia after having dissembled the nature and extent of a head injury. Her family was well aware that neither claim was accurate and that she was not disabled either by lumbar or brain pathology. However, her case is a cautionary tale of the need for careful, agnostic evaluation of the data, particularly in complex cases with complex histories. For example, Ms. Neely's history of severe physical injuries was repeatedly accepted in later medical records without apparent consideration of the prior medical records, consultation with prior providers, collateral history from family members, or even additional physical and cognitive evaluations that could have shown malingered symptoms.

Unfortunately, systematic reading of patients' medical records, especially those with long, complicated histories, will often find misinformation that is continued in subsequent charts. This may not only be because of the patient's mendacity, as in Ms. Neely's case. Providers may also confabulate aspects of patient's histories, especially around psychiatric issues, in medical charts. In psychiatric records, one can find personalized, pejorative and even bizarre statements in patient charts, particularly patients perceived to be unpleasant, difficult, confusing, and/or unrewarding to treat. Often, these are individuals with histories of complex developmental trauma. Most clinicians lack trauma-informed training to make sense of problematic patient behavior based on posttraumatic reactivity of which the patient him or herself may also be unaware (Blank, 1985). Once the posttraumatic origins of the problematic behavior are understood by both the patient and treating clinicians, relatively common-sensical trauma-informed interventions may resolve these difficulties, even relatively rapidly (Olafson et al., 2018; Saltzman et al., 2017).

A considerable body of data has found that, as is common in general of survivors of childhood abuse and neglect, DID individuals are vulnerable to later sexual, emotional, and physical 
exploitation. This is particularly the case where there is a mixture of attachment and betrayal (Freyd, 1996, 1997), making therapist malpractice/misconduct, primarily sexual exploitation, a common form of psychological injury to the DID individual (Kluft, 1990b; Myrick et al., 2013; Snyder, 2018; Webermann, Brand, \& Chasson, 2014; Webermann et al., 2017). In these cases, there may be a range of therapist misbehavior, from troubled mental health providers whose own psychological/ psychiatric pathology is central to the misconduct, to psychopathic individuals who engage in serial sexual, financial, and other misconduct with many vulnerable patients (Boodman \& Davis, 2003; Pope, 1989). Also, DID individuals' vulnerability to revictimization readily make them targets of bullying, sexual harassment, and/or sexual misconduct at work, school, sports activities, the military, religious institutions, and in other settings. All of these may lead to civil, administrative, and/or disability claims (Classen et al., 2005; Noll, Horowitz, Bonanno, Trickett, \& Putnam, 2003; Salter, 2017).

Despite Ms. Neely's history of antisocial behavior and mendacity, her description of the therapist who reportedly engaged in substandard care: exorcisms, boundary violations, regressive practices, etc. fits the pattern of therapist misconduct in many cases like this, with or without sexual abuse of the patient. Ms. Neely was said to be desperately wanting a positive maternal figure. A major aspect of the inappropriate therapy was the therapist encouraging Ms. Neely to call her "mommy" and suckle at a bottle given to her by the therapist, as well as other actions in the therapist's highly misguided attempt to literally "repair" reported abuse and neglect by Ms. Neely's mother. As described above, some of Ms. Neely's subsequent behavior in therapy is similar to those of other DID individuals who have experienced therapist misconduct.

Clinically, this is a common, hidden source of treatment stalemate and impasse for DID patients. The setting of therapy itself has now become a posttraumatic phobic stimulus, rather than a potential safe space. Invariably, subsequent therapists emit some specific reminder of the prior exploitative provider: in dress, words, facial expression, etc. This can literally result in a flashback related to therapy itself, if not more subtle posttraumatic responding. DID individuals may have such extreme shame and self-blame responses to this circumstance, that, in clinical or forensic interviews, they will only admit to having experienced prior therapist exploitation when explicitly asked about it.

In the author's experience, DID individuals' ability to work in subsequent psychotherapy may be severely compromised by prior therapist misconduct, leading to marked prolongation of the treatment course. Accordingly, in malpractice cases, damages should include that subsequent treatment needs for the DID plaintiff are likely to be greatly expanded, both for outpatient psychotherapy, psychopharmacological management, and treatment at more restrictive levels of care.
Competence, Criminal Responsibility, and DID Defendants

Courts have diverged in findings of competence to stand trial (CTS) and criminal responsibility (NGRI or NCR) for DID defendants based on differing ways of viewing the disorder (Behnke, 1997b). At least one district court rejected DID as a valid diagnosis to be considered for an insanity defense plea, but this ruling was reversed on appeal (Lewis \& Bard, 1991). Both trial and appeals courts in state and federal jurisdictions have ruled that DID meets Frye and/or Daubert criteria so it may legitimately be used as a criminal defense, as well as that DID individuals can testify in court experiencing themselves as specific self states (Armstrong, 2001; Mao, 2019).

In criminal cases, Mens rea, the state of mind indicating culpability for criminal acts, may seem hard to determine in an individual who claims dense amnesia for crimes and/or who experiences him/herself as dissociative self states that variously profess or deny responsibility for criminal behavior (Armstrong, 2001; Behnke, 1997a, 1997b; Lewis \& Bard, 1991; Sinnott-Armstrong \& Behneke, 2001). Some legal scholars have suggested that, in jurisdictions that allow it, a DID defendants' behavior may allow an actus reus defense based on the inability to control one's actions, as in crimes committed in epileptic or somnambulistic states (personal communication, Alan Scheflin, J.D., L.L.M, March 14, 2008, Baltimore, MD; see Gravely, 1982). In a recent highprofile criminal case, a defendant who shot an alleged past abuser used severe depersonalization - an out of body experience- as a psychiatric defense. He was found not criminally responsible, based on involuntary action. That defendant did not claim a diagnosis of DID (Blair, 2002).

DID defendants may not be able to give reliable testimony in their own defense due to amnesia and lack of awareness of the behavior of self states. Conversely, questions can be raised as to whether the DID individual's self states can be called to give testimony as "independent" witnesses on behalf of the defendant. When the DID individual is the alleged victim of a crime, similar questions may arise about whether the DID individual is competent to give testimony in court, either as a "whole" human being or as self states testifying as separate entities. In a recent Australian criminal case, a woman diagnosed with DID testified, as several different self states, that her father had subjected her to years of extreme sadistic sexual, emotional, and physical abuse. Based largely on her testimony - in part confirmed by other family members, physical evidence, and the father's prior record of convictions for sexual crimes - her father was convicted of multiple counts of childhood rape and sentenced to 45 years in prison (Mao, 2019).

Often, the conflation of DID self states with separate people has led to legal rulings based on the question of which self state was in charge of committing the crime, and how to view 
the "uninvolved" self states with apparent amnesia for the crime (Behnke, 1997b). Behnke describes three analyses that the courts have used in this regard. The first tests the mental state of the "alter that was out [in control of the body]" at the time of the offense. The second tests the mental state of the "host" alter at the time of the crime. The third attempts to test the mental state of "all of the alters" at the time of the crime. The latter has sometimes devolved into attempts to evaluate the mental state of each self state at the time of the crime. One extreme legal theory posits that DID self states should be treated like separate individuals so that those "uninvolved' in criminal behavior would, by definition, be absolved of responsibility, and a finding of not guilty by reason of insanity would be mandated (Saks, 1997; Watkins, 1976). The fundamental problem with this view is illuminated in the apocryphal rejoinder of a judge responding to an alleged DID murder defendant, "We'll send the ones of you who did it to jail, and the rest of you can go free."

The main critique of these forensic conceptualizations of DID is that courts, forensic evaluators, and attorneys have reified the self states, confounding their cognitions and behaviors with those of separate persons and failing to view the self states as psychobiological entities developed in the mind of an individual human being (Armstrong, 2001; Behnke, 1997a, 1997b; Kluft, 1988; Lewis \& Bard, 1991; Loewenstein et al., 2017; Loewenstein, 2018; Putnam, 1988; SinnottArmstrong \& Behneke, 2001).

Armstrong (2001) and others posit that the clinical standard of holding the "whole human being" responsible for the behavior of any self state should be the foundation for the evaluation of DID criminal defendants (Simeon \& Loewenstein, 2009), notwithstanding claims of amnesia or lack of agency. Clinically, this stance is associated with progress and improvement in adaptive functioning (Brand, McNary, et al., 2012; Brand, Myrick, et al., 2012; Brand, Schielke, et al., 2019). Failure to hold the whole human responsible for behavior usually results in regression and treatment stalemate (Beahrs, 1994; Brand, Loewenstein, \& Lanius, 2014; International Society for the Study of Dissociation et al., 2011). An affirmative case should be made that the DID defendant, as the whole human being, meets the standard for incompetence to stand trial, NGRI/NCR, diminished capacity, etc., just as would be the case for any psychiatric defendant (Behnke, 1997a, 1997b; Sinnott-Armstrong \& Behneke, 2001).

\section{The Hillside Strangler}

The Hillside Strangler case (1977-1983) was a highly publicized, major criminal case involving contentious expert clashes about MPD/DID. It represents a paradigmatic portrayal of the conflicts that can arise about CTS and NGRI and MPD/DID, particularly when forensic experts conceptualize
DID self states as essentially equivalent to separate people. As will be discussed, Ms. Neely's own, often compelling reification of self states was a significant factor in the difficulties forensic examiners had in assessing her for CTS/NGRI.

The battle of the experts in the Hillside Strangler case prefigured major debates among academics, legal theorists, and the public about dissociation, DA, and DID that culminated in the early 1990s with the rise of false memory syndrome (FMS) (see Loewenstein et al., 2017). The major expert witnesses, John Watkins, Ph.D., and Martin Orne, Ph.D., both with extensive academic and clinical backgrounds in hypnosis, were opponents in their views of hypnosis, dissociation, childhood sexual abuse, DA, and MPD/DID. Watkins was a pioneer in the diagnosis and treatment of dissociative and posttraumatic disorders (Watkins \& Watkins, 1984, 1988). Orne later became a prominent member of the academic advisory board of the False Memory Syndrome Foundation (FMSF), opposing the validity of DID and DA ("recovered memory"), and discounting the prevalence and importance of reports of childhood sexual abuse (Orne, Whitehouse, Dinges, \& Orne, 1988; Karlin \& Orne, 1996).

In the Hillside Strangler case, two cousins, Kenneth Bianchi and Angelo Buono, were arrested for the serial rape, torture, and murder of 10 women in the Los Angeles area between 1977 and 1978. The women were left posed and naked on hillsides, terrorizing the community (George, 2000). In January 1979, Bianchi was arrested in Bellingham, Washington, and charged with the rape and murder of two other women. His apparent behavioral problems led his attorneys to request a forensic psychological evaluation, provided by John Watkins, Ph.D. During Watkins's extended examination, Bianchi confessed to the Hillside Strangler murders and also implicated his cousin. However, Bianchi claimed that his crimes were "really" committed by an evil self state named "Steve." Five different psychological and psychiatric forensic experts provided opinions on Bianchi's diagnosis and mental state during the crimes. Most important was the clash between Watkins and Orne, the major forensic experts for the defense and the prosecution, respectively.

Watkins insisted that his extensive record review, history, and forensic examination of Bianchi, including repeated hypnotic sessions and psychological assessment, conclusively supported the diagnosis of DID (then MPD), and, ipso facto, the finding of lack of criminal responsibility. Watkins believed that, in terms of criminal responsibility, all MPD/DID defendants manifested relatively separate entities, one innocent and one criminal, leading to findings of NGRI (Watkins, 1976). Watkins described two self states said to exist in Bianchi: "Ken," who was complaisant and unassuming, and "Steve," a sadistic, sexual psychopath who confessed to the murders (Watkins, 1984). Subsequently, Orne did his own comprehensive examination, including review of the psychological assessment measures; evaluations of Bianchi in 
apparent hypnotic states; and eliciting ostensible switches between the purported self states. Ultimately, Orne opined that Bianchi met DSM-III (American Psychiatric Association, 1980) diagnostic criteria for antisocial personality disorder and sexual sadism and was malingering both MPD/DID and being in a true hypnotic state (Orne et al., 1984).

Both Watkins and Orne assessed the purported self states as if these were separate people. Although disagreeing on many other aspects of the case, both Watkins and Orne conceptualized DID consistent with the DSM-III diagnostic criteria for DID, which were very different from all subsequent DSM diagnostic criteria (see Loewenstein et al., 2017 for a discussion of the evolution of the ICD and DSM diagnostic criteria for DID). Orne et al. (1984) opined that, in bone fide DID: "(a) [T]he structure and content of the various personalities should have been consistent over time, (b) the boundaries between different personalities should have been stable and not readily altered by social cues, (c) the response to hypnosis should have been similar to that of other deeply hypnotized subjects, and (d) those who had known [Bianchi] over a period of years should have been able to provide examples of sudden, inexplicable changes in behavior and identity, and evidence to corroborate his claimed intermittent amnesias" (page 118, italics added).

Watkins administered the Rorschach separately, twice to Bianchi, purportedly as each self state, as if he was entirely different people. Testing was scored blindly by defense and prosecution Rorschach experts, who were not told that these were different protocols from the same human being. Watkins' expert opined that the testing showed definitive manifestations of different people: a mildly "neurotic" person (K) and a murderous, sexually sadistic, extremely ill, possibly schizophrenic, criminal (S) (Watkins, 1984). Orne's assessor concluded that the tests showed different aspects of the same, sociopathic person (Orne et al., 1984). After Orne's examination prevailed, Bianchi pled guilty, admitted his malingering and, in exchange for leniency, agreed to testify against Buono, (George, 2000). After a lengthy trial, both men were convicted and sentenced to life in prison.

\section{Factors Affecting Forensic Assessment of DID}

Little systematic data has been acquired about DID individuals in the criminal justice system, except case series (Lewis et al., 1997), and a case series of male DID patients, about half of whom had criminal justice involvement, either for major, violent felonies or for less severe crimes like drunk and disorderly conduct, although female DID individuals also reported engaging in violent and even homicidal behavior (Loewenstein \& Putnam, 1990). A recent study of all 82,500 prison inmates in Taiwan found that ICD-10 dissociative disorder diagnoses were the most common in both males and female inmates (Tung, Hsiao, Shen, \& Huang, 2019).
With information about DID increasingly available in academic publications and popular media, feigners may develop more sophisticated ways of imitating DID symptoms and its clinical presentation (Brand, Armstrong, et al., 2006; Brand, McNary, Loewenstein, Kolos, \& Barr, 2006; Brand, Webermann, et al., 2016; Kluft, 1991). In general, authorities agree that "authentic DID defendants are more likely to show a complex self state system, not just a "good/bad" self -state dichotomy with putative self states that do not manifest outside of the claim of non-responsibility (Brown \& Scheflin, 1999; Kluft, 1987c). In addition to disavowal of responsibility by blaming self states for behavior, some DID individuals, both in clinical and forensic settings, may feign greater severity of DID symptoms, such as more extreme dissociative amnesia (Scott, 2012), report factitious trauma histories, or lie about other aspects of their life history (Brand, Webermann, et al., 2016; Brand, Schielke, \& Brams, 2017; Brand, Schielke, Brams, et al., 2017; Brown \& Scheflin, 1999; Kluft, 1987c). Bone fide DID defendants may have bizarre, idiosyncratic explanations for why and how they (as different self states) committed crimes, not just that "the bad one did it" (Armstrong, 2001). However, as with psychotic defendants, bizarre, idiosyncratic thinking does not necessarily compel the finding that DID defendants are incompetent to stand trial, NGRI, NCR, etc. (Armstrong, 2001).

Some genuine DID defendants minimize their psychiatric symptoms and attempt to avoid being labeled psychiatrically ill. Others may behave in self-defeating ways that can undermine their defense (Kluft, 1987c; Lewis et al., 1997). Complicating assessment is the phenomenon of "imitative DID," in which individuals, their concerned others, and even their treatment providers believe in the person's inaccurate DID diagnosis, with the person building a life around the diagnosis and being a survivor of childhood trauma (Draijer \& Boon, 1999). A body of research has attempted to distinguish feigners, including DID individuals who feign aspects of their disorder, on a variety of standard clinical and forensic measures. A group of psychological assessment measures, and an approach to assessing dissociation on these, has been developed that can aid in the differential diagnosis of feigned DID, imitative DID, and genuine DID augmented by feigning (Brand, Armstrong, et al., 2006; Brand, McNary, et al., 2006; Brand, Tursich, et al., 2014; Brand, Chasson, et al., 2016; Brand, Schielke, \& Brams, 2017; Brand, Schielke, Brams, et al., 2017; Brand et al., 2018; Brand, Webermann, et al., 2019; Vissia et al., 2016).

As in all forensic psychiatric assessment, it is the totality of the data that will determine forensic opinions: clinical assessment; corollary history; comprehensive review of psychiatric, medical, social service, prison, and educational records; police reports, deposition and witness testimony; forensic laboratory data; and psychological assessment measures. In some cases, extended periods of observation have been required to successfully assess partial or complete feigning in purported DID individuals (American Academy of Psychiatry and the Law, 2015; 
Brown \& Scheflin, 1999; Kluft, 1987c). As in the assessment of any psychiatric defendant, one must consider the presence of co-morbid disorders and factors such as the planning or impulsivity of the crime (Armstrong, 2001; Bourget \& Whitehurst, 2007; Bourget, Gagne, \& Wood, 2017).

\section{The Forensic Assessments of Ms. Neely}

In the four forensic evaluations, much of the same data were described concerning Ms. Neely’s past, personal, clinical, and legal history, but the conclusions were discrepant (see Table 3).

\section{The State}

Diagnosis Ms. Neely had forensic assessments and reports from the state forensic psychiatrist, psychologist, neurologist, and a physical therapist. She was extraordinarily difficult to interview, with substantial variability in clinical presentation, apparent access to memory, and ability to ambulate. The neurological and physical therapy evaluations confirmed the findings that her apparent weakness varied considerably and was not associated with any known neurological pattern.

When the forensic evaluators attempted to take a narrative history of the alleged offenses, Ms. Neely denied that she could have set the witnessed fire because she never went anywhere without her leg braces. She absolutely denied setting the fire at her former therapist's home. When the interviewer asked more about her possible culpability in the fire at Ms. Brown's home, Ms. Neely switched to a child self state and became non-responsive to questions. When it was decided to take her back to her room, Ms. Neely began to bang her temples with her fists. When approached by male staff to contain the behavior, she bolted out of the chair, ran down the hall, and attempted to break the barred windows. Later, calmer and more grounded, she met with the unit psychiatrist. She both denied recall of the event yet seemed to recall it in detail.

Table 3 Forensic psychiatric expert conclusions

\begin{tabular}{|c|c|c|c|c|}
\hline Findings & State examiner & $\begin{array}{l}\text { Defense } \\
\text { expert }\end{array}$ & $\begin{array}{l}\text { Court expert } \\
\# 1\end{array}$ & Author \\
\hline \multicolumn{5}{|l|}{ Diagnoses } \\
\hline $\begin{array}{l}\text { DSM IV-TR Axis } \\
\quad 1\end{array}$ & $\begin{array}{l}\cdot \text { UDS } \\
\text { - Factitious } \\
\text { disorder } \\
\text { - Malingering }\end{array}$ & $\bullet$ DID & $\begin{array}{l}\cdot \text { DID } \\
\cdot \text { PTSD } \\
\cdot \text { MDD } \\
\cdot \text { UDS } \\
\cdot \text { Malingering }\end{array}$ & $\begin{array}{l}\text { - DID } \\
\text { - Complicated by single-episode GDA } \\
\text { - PTSD } \\
\text { - MDD, S/R } \\
\text { - CD with motor and sensory symptoms } \\
\text { - SPD chronic, site lower back } \\
\text { - Malingering with exaggeration of symptoms of DID } \\
\text { - Malingering of amnestic disorder secondary to general medical condition } \\
\text { - Malingering with exaggeration of somatic and somatoform symptoms }\end{array}$ \\
\hline $\begin{array}{l}\text { DSM-IV-TR Axis } \\
\text { II }\end{array}$ & $\begin{array}{l}\mathrm{BPD} \\
(\mathrm{ASD})^{1}\end{array}$ & & $\begin{array}{l}\text { BPD } \\
(\mathrm{ASD})^{1}\end{array}$ & $\begin{array}{l}\text { - Personality disorder NOS with severe antisocial and paranoid features; } \\
\text { avoidant features }\end{array}$ \\
\hline \multicolumn{5}{|l|}{ Competence } \\
\hline Rational capacity & Yes & No & No & Yes \\
\hline $\begin{array}{l}\text { Factual capacity } \\
\text { Insanity } \\
\text { Fire \#1 }\end{array}$ & Yes & No & Yes, and no ${ }^{3}$ & Yes \\
\hline $\begin{array}{l}\text { Appreciate } \\
\text { criminality }\end{array}$ & Yes & No & Yes & Yes \\
\hline Conform conduct & Yes & No & Yes & Yes \\
\hline \multicolumn{5}{|l|}{$\begin{array}{l}\text { Insanity } \\
\text { Fire \#2 }\end{array}$} \\
\hline $\begin{array}{l}\text { Appreciate } \\
\text { criminality }\end{array}$ & Yes & No & $\begin{array}{l}\text { Insufficient } \\
\text { data }\end{array}$ & Yes \\
\hline Conform conduct & Yes & $\begin{array}{l}\text { Insufficient } \\
\text { data }^{2}\end{array}$ & $\begin{array}{l}\text { Insufficient } \\
\text { data }\end{array}$ & Yes \\
\hline
\end{tabular}

Abbreviations: $A S D$ antisocial personality disorder, $B P D$ borderline personality disorder, $C D$ conversion disorder, $D I D$ dissociative identity disorder, $G D A$ generalized dissociative amnesia, $P T S D$ posttraumatic stress disorder, $M D D$ major depressive disorder, $M D D S / R$ major depressive disorder (severe, recurrent), SPD somatoform pain disorder, $U D S$ undifferentiated somatoform disorder

${ }^{1}$ Antisocial personality disorder possible, but definitive diagnosis requires records prior to age 18 , which are unavailable

2 "likely an event ...that Doris could not control"

3 “... [S] he will unpredictably find herself during the course of the proceedings in states in which she has lost access to the knowledge needed to provide an understanding of the proceedings" 
When questioned about this, she became defensively externalizing, blaming the unit and the staff and insisting she "was here for treatment of my DID."

When she was able to participate in testing, she exhibited switching behavior with highly variable access to information. When questioned about this, she became defensive and threatened to end interviews. She had highly variable responses to psychological assessments. She took an inordinate amount of time on several measures, e.g., the Structured Interview for Reported Symptoms (SIRS) (Rogers, Bagby, \& Dickens, 1992), although she did not fall in the definite feigning range. Due to the excessive amount of time it took Ms. Neely to respond to questions, the assessor gave up on administering the Structured Clinical Interview for DSM-IV Dissociative Disorders (Steinberg, 1994), a semi-structured diagnostic interview generally accepted as the "gold standard" for the diagnosis of dissociative disorders, including DID.

Ms. Neely answered difficult questions correctly, but not simple ones. For example, she denied ability to read a digital watch but could easily draw an analog clock and number it correctly, but then she put in the incorrect time by reversing the hands. She scored over 80 on the Dissociative Experiences Scale (DES) (Bernstein \& Putnam, 1986), an exceptionally high score generally associated with a "cry for help" pattern or deliberate exaggeration or feigning. Ms. Neely had a high probability of being in the "pathological dissociation" taxon (DES-T) that comprises individuals that meet diagnostic criteria for DID or similar severe dissociative psychopathology (Waller, Putnam, \& Carlson, 1996). ${ }^{4}$

On the Trauma Symptom Inventory (TSI) (Briere, Elliott, Harris, \& Cotman, 1995), Ms. Neely had an invalid profile because she did not answer questions about sexuality. On a retest by the defense expert, she again had an invalid profile but wrote cogent comments about her responses in the margin. $^{5}$ Several other measures were invalid due to failure to answer a substantial number of questions. In totality, the state's expert opined that Ms. Neely did not meet diagnostic criteria for DID because of her highly variable claims of amnesia. The state's psychological expert also wondered if the DID diagnosis had been so reinforced by "suggestive" prior treatment that even the notable switching behaviors could be better conceptualized as feigning. Further, she made the diagnosis of Undifferentiated Somatoform Disorder but was unable to rule out consciously feigned somatic symptoms. She opined that Ms. Neely met criteria for BPD, and could meet

\footnotetext{
$\overline{4}$ The DES is the most widely used screening instrument for trait dissociation and has been translated into numerous foreign languages. A score of 30 or above has very good predictive power for a diagnosis of DID or related conditions in the DSM-5 system, similar to the first example of Other Specified Dissociative Disorder (OSDD). For a fuller discussion, please see Lyssenko et al. (2017); van Ijzendoorn and Schuengel (1996); Spiegel et al. (2011).

${ }^{5}$ See Palermo and Brand (2019) for a discussion of the TSI and feigning in evaluation of dissociative disorders.
}

criteria for Antisocial Personality Disorder, as there were no data concerning the necessary history of antisocial behavior prior to age 18 .

Competence The state psychiatrist reviewed all the testing, neurological data, and his own psychiatric interviews, and concurred with these diagnostic conclusions. He opined that Ms. Neely had both the factual and rational understanding to meet the competency standard. He stated that when Ms. Neely was questioned directly about matters related to competency or legal insanity, she professed ignorance, amnesia, and confusion and made grossly incorrect statements, e.g., that she could not have committed a crime that she did not recall. However, when not being questioned directly, Ms. Neely had excellent recall, advocated strongly for her "rights" in the hospital, deflected responsibility for behavior, and remained without dissociative state changes through even long, stressful interactions. At these times, she appeared shrewdly aware of the legal system and her interactions with her attorney.

Sanity In terms of questions concerning legal insanity, the report continued, “...[Ms. Neely's] statements indicated that she knew that fire setting was wrong and there is no evidence that she suffers from delusions or hallucinations that would impair her ability to appreciate wrongfulness... She has been able to follow complex rules and conform behavior in a stressful situation... with few exceptions. The theory of complex actions occurring in an altered state is not supported by the psychiatric diagnoses made by the [State Hospital] treatment team and myself...For these reasons...I cannot support a finding of insanity at the time or that she lacked the mental state for the alleged crime."

\section{The Defense}

Diagnosis The forensic psychologist for the defense had considerable experience in the clinical and forensic assessment of DID. His opinions were diametrically opposed to those of the State Hospital team. He conducted lengthy videotaped interviews with Ms. Neely, who had been transferred to state prison. He administered psychological assessment measures, some of which overlapped with those of the state hospital.

His report began with a series of questions, but the main diagnostic question was dichotomous: does Ms. Neely "have" DID, or is she malingering. He described a plethora of data that led him to conclude the DID diagnosis was accurate. In addition to the findings of his own extended videotaped diagnostic assessment, he cites the historical data from Ms. Neely's 20+ years of medical records documenting essentially the same named self states, switching behaviors, dense but state-dependent dissociative amnesia, and symptoms and signs of DID that feigners would be unlikely to demonstrate, 
e.g., headaches in response to internal conflict among the self states or sudden, brief dissociative memory lapses that occur during clinical interviews, sometimes termed "micro-dissociations" (Loewenstein, 1991a). He notes that many nonclinical observers: neighbors, the patient's husband and sons, Ms. Neely's attorney, in addition to virtually all previous clinicians, have reported interacting with essentially the same groups of self states, witnessed seemingly uncontrolled switching behaviors, chronic complex dissociative amnesia symptoms, etc. He points out that even the state hospital assessment team documented these same findings, although these evaluators interpreted the symptoms as indicia of malingering or the results of suggestive therapies. He reports that Ms. Neely's attorney was so baffled by his client that he attended a workshop on DID with one of the world's experts, Richard P. Kluft, M.D., Ph.D. Further, this assessor persisted in having Ms. Neely complete the SCID-D assessment, with findings supporting the DID diagnosis.

Competence The defense evaluator concluded that Ms. Neely lacked both the factual and rational capacities that underlies a finding of CTS. He based this on what he viewed as uncontrolled, unpredictable switching among self states. Even if some self states could meet the test for competence, others clearly did not. There was no way to assure that the relevant self states could be accessed when needed, or that adequate continuous memory for facts and information would be available. He noted that a seemingly minor, common environmental sound regularly produced an "uncontrolled switch" to a disoriented, confused child state. Once this state was "forward", Ms. Neely was very difficult to reorient to a more grounded, better adapted state. On video, he documented an event when he was inquiring of Ms. Neely whether there was any internal "control" over switching. Ms. Neely suddenly switched to a violent self state, became highly agitated, banged on the walls with her fists, and finally attacked the camera. Guards entered the interview room to restrain Ms. Neely and the interview ended. Based on these, and similar observations, the evaluator concluded that relatively minor, even irrelevant stimuli could provoke highly maladaptive, uncontrolled, unpredictable switching behaviors that could disrupt interactions with Ms. Neely's attorney, as well as in court. Thus, he deemed Ms. Neely incapable of consistently understanding the proceedings or rationally collaborating with counsel.

The expert cited his own theory that the test for whether a DID individual is CTS or NGRI depends on the idea of "coherence" of the self-state system. He described "Doris" as the "core personality" that had no ability to control switching behaviors. Further, he described what appeared to be major amnestic barriers and lack of control of switching among all other self states disrupting Ms. Neely's ability to participate meaningfully in the legal process.
Insanity The defense expert used similar reasoning to support a finding of NGRI for both charges, although Ms. Neely consistently and completely denied the second charge. He reports that, when asking about her mental state at the time of the observed fire-setting, Ms. Neely described the following as the Jeffrey state: "Me and one other [self state] had spotted a person who had hurt Doris in the past at least we thought it was the same person. We'd saw this person like a week or so earlier so we tried to follow them home - so I had an idea where they lived at. ...When [Doris] was out driving that morning, I decided to go back [and] pay that person a visit to let them know what they did was not all right in any way. I went with intent to harm that person, not their home, so went in, that's when we did something else, then this other person comes down the hallways I just think, oh shit it's the wrong person so I had to get the hell out of there." The author asked "Jeffrey" about the "something else" that happened and he reported, "Someone else came out and started the fire. I think at that time when the other guy, the kid came out, someone else [the other self state] got startled so they went back in [to the mind] and left me there." This description, with references to the experience of switching, and of states as if they were separate people, and to the self as plural, or third person singular or plural, is consistent with the way many DID individuals describe the experience of multiplicity (Loewenstein, 1991a).

The defense expert concludes that "Doris," "the core personality," cannot "appreciate" the wrongfulness of conduct she cannot recall, hence meeting the first NGRI test. The seemingly "bizarre" description of the witnessed fire-setting (above) underlies the lack of "coherence" among Ms. Neely's self states. Accordingly, because of this apparent uncontrolled switching, Doris cannot conform conduct since Doris cannot predict or control emergence or departure of any other self state, let alone recall her behavior when it is under the sway of these chaotically shifting states.

\section{First Court-Appointed Forensic Evaluation}

Given these highly divergent opinions, the court, with agreement of the prosecution and defense attorneys, appointed a prominent forensic psychiatrist as an independent expert to evaluate Ms. Neely. He did not hold himself out as an expert in DID, but neither did he hold skeptical views of the existence DID. He had considerable experience in the forensic assessment of PTSD.

Diagnosis He reviewed all the data from Ms. Neely's clinical and forensic records and conducted lengthy interviews with her. He also obtained collateral information from Mr. Neely, Ms. Neely's attorney, and the law enforcement officers who arrested her for the current charges. Ms. Neely's attorney described having substantial difficulties attempting to work with 
a client who claimed amnesia for, or denied committing even witnessed crimes, switched rapidly among various self states, and appeared not to assimilate basic information necessary to assist with her defense.

During his interviews, the independent expert encountered switching behaviors among several of Ms. Neely's self states, with the same names, characteristics, and repertoire of behaviors that had been described in all prior accounts. After evaluating all existing data, he agreed with the accuracy of the diagnosis of DID, although he carefully considered the kinds of discrepant data that were central in the state hospital's determination of malingering. He agreed that Ms. Neely malingered aspects of her non-medically explained physical symptoms, but stated that some of these symptoms could be understood as a manifestation of a conversion disorder.

His views of DID led to his opinions about CTS and NGRI.

Competence His opinions regarding Ms. Neely's CTS were that Ms. Neely demonstrated sufficient factual understanding of the extant legal matters, but that the unpredictable and uncontrolled switching behaviors made her unable to have sufficient, continual rational understanding to consult with her attorney both in individual consultations and in the courtroom. The amnesia was too great, and it was impossible to predict which self state knew relevant information, and which state would emerge in court.

Legal Insanity With respect to NGRI, he based his opinions on the following analysis: He had no way of assessing Ms. Neely's mental state at the time of the fire at Ms. Brown's home, nor could he see a "reality-based motive" for that crime. Accordingly, he could not determine whether Ms. Neely could either appreciate wrongfulness or control conduct during that event.

On the other hand, given the data about the witnessed fire, Ms. Neely's response of, "I'm sick," clearly indicated an attempt to explain her behavior, and her comprehension at the time "that there was something to be explained." With this comment, it could be inferred that Ms. Neely was attempting to disavow responsibility for her behavior.

Further, in past clinical settings, when approached or touched by males in a stressful situation, Ms. Neely had dissociated into the wildly disoriented Dorrie state. In other stressful situations, she had dissociated into dyscontrolled, rageful self states that have destroyed property and/or engaged in extreme forms of self-mutilation. In contrast, when the witness to the fire let go of Ms. Neely's arm, she is described as calmly walking out of the house and driving away. Accordingly, this expert opined that Ms. Neely did not meet criteria for NGRI on these charges.

$\mathrm{He}$ also suggested an additional evaluation by someone with extensive experience in the diagnosis and treatment of DID. Accordingly, with the agreement of both the state and the defense attorneys, I performed the second court-ordered forensic evaluation of Ms. Neely.

\section{Second Court-Ordered Evaluation-by the Author}

Assessment of Ms. Neely I reviewed all the available medical, law-enforcement, correctional, forensic, and psychiatric records, including videotaped police interviews and an edited version of the defense expert's videos. I reviewed the three prior expert forensic reports and the psychological assessment reports, including score-sheets and raw data. I also reviewed emails sent by Ms. Neely to Ms. Brown. I interviewed Ms. Neely for about $20 \mathrm{~h}$ over 4 days and also interviewed $\mathrm{Mr}$. Neely and one of their adult sons for $2 \mathrm{~h}$. I interviewed Ms. Brown for about $2 \mathrm{~h}$. Also, I interviewed Ms. Neely's attorney, as well as medical and nursing staff of the state hospital. Initially, Ms. Neely resisted consenting to my interviewing her past mental health providers. Her lawyer insisted that she give consent, and she reluctantly did so. I interviewed six of Ms. Neely's prior treatment providers by phone, going back to the clinician who initially made the DID diagnosis. I asked Ms. Neely to complete the self-report diagnostic inventory, the Multidimensional Inventory for Dissociation (MID) (Dell, 2006a, 2006b). As with other instruments, Ms. Neely left much of the questionnaire blank, invalidating the measure.

In assessing Ms. Neely, I was not particularly interested in the manifest presentational differences of the self states. Rather, I wanted to understand the self states' subjective "personal" history, functions, and the extent to which both pathological and resilience factors would manifest within particular self states, across the self-state-system, and across "the whole mind."

Interviewing Ms. Neely The first 2 interviews lasted only about $2 \mathrm{~h}$ each, as hospital administration mandated that Ms. Neely be interviewed on the inpatient unit. She was inhibited from fully answering questions due to the objectively loud unit and the requirement of an open door for 1:1 observation brought about by her repeated dangerousness to self. Ms. Neely began with a litany of paranoid-sounding complaints. She was being lied to, tricked, railroaded. She refused to allow me to videotape her, as the defense expert had done, stating that the taping would be used against her. She declared that she was being targeted in the hospital unit. She was hypervigilant, and, at one point, suddenly demanded to know if I had a secret recording device under my papers. She querulously perseverated about Ms. Brown. How could she think Ms. Neely would have attempted arson at her home? It was Ms. Brown who had insisted on the termination meeting, on keeping in contact with Ms. Neely after the end of treatment. Why did she threaten a restraining order if Ms. Neely did not stop calling her? How could she have set the fire, as it was discovered while she was at the police station being interrogated, etc. 
Initially, she said that I must be there to help her get admitted to the Trauma Disorders Program at Sheppard Pratt. I explained that this was impossible. She began to perseverate that she had been lied to by her lawyer, the defense expert, and others who had "promised" that meeting with me was solely to assist her in transferring to a hospital that would "help" her. In my interview with her attorney, he said he had repeatedly conveyed the correct information to Ms. Neely, but somehow it was never retained. He said that this was typical of the problems Ms. Neely presented as a client. She could not seem to collaborate with him on the legal issues.

Across all interviews, just as in all prior police and forensic interviews, Ms. Neely never expressed concern about Ms. Brown, her pets, the damage to her home, etc. Referring to the arson resulting in her arrest, she told me that, when brought to the police station, her first question was, "was anybody hurt?" As noted above, her first question, actually, was whether the young man who caught her had said she was using her crutches.

As prior interviewers found, when I attempted to ask any direct question bearing on her legal situation, Ms. Neely would shift topics, appeared to experience blocking, responded irrelevantly, and/or denied that the questions had any relationship to her situation. She would rock, moan, cover her ears, stare off blankly, and become mute. At this point, I decided to engage by talking over to Ms. Neely's self states, as I would a putative DID patient in a clinical situation. Also, this was one of the myriad ways that I attempted to indirectly assess the DID diagnosis. As I did so, Ms. Neely began to respond in ways typical of DID. I asked her about inner voices, inner conflict, and inner prohibitions on answering my questions. In particular, whenever I approached a sensitive topic, Ms. Neely reported voices telling her, "move on," "we're not answering that now," etc. She described thought insertion, removal, made impulses, blackouts, finding unexplained possessions, being told of behavior-even positive behavior - she did not recall, and other symptoms pathognomonic for DID. She repeatedly referred to herself in the first person plural and third person singular and plural.

I observed typical DID phenomenology of overlap and interference between self states, such as subtle facial changes including appearing more childlike, variable eye contact with eyes darting to the side as if listening to voices, eyelid fluttering, rapid blinking, touching her face when she admitted hearing voices, shifting posture, leg shaking, then stopping shaking, appearing frozen, etc. (Armstrong, Laurenti, \& Loewenstein, 1991).

As I tracked her responses, far from the chaotic, incomprehensible presentation described by prior evaluators, I quickly was aware that Ms. Neely's behavior was not random, but purposive. This included her refusals to answer when the "voices" insisted, as well as suddenly appearing to go into a trance, saying the inner voices were getting too "loud inside," that she had forgotten what had just been asked, etc. This occurred primarily when I approached any question that might bear on the crimes with which she was charged, her understanding of legal processes like CTS, etc. Similarly, she emitted these dissociative symptoms/behaviors when I asked questions related to interactions between self states, control over state switching, and subjectively experienced relationships among self states. I became aware, behind the apparent "surface" chaos, of a hypervigilant awareness that was observing me and appearing to be carefully calibrating Ms. Neely's responses: "Move on. Next question." Even the surface Doris state clearly had more internal communication and inner awareness than had been previously described.

After the first two abortive interviews, the hospital administration allowed me to interview Ms. Neely in a room off the unit, with staff sitting outside the closed door. During the next six-hour interview, Ms. Neely, as Doris, described and demonstrated a panoply of dissociative symptoms pathognomonic for DID: chronic complex dissociative amnesia; marked forms of passive influence; spontaneous age-regression experiences; blocking; micro-dissociations during the interview; hearing voices in her mind that she identified as those of specific named self states; descriptions of PTSD symptoms; and cues for intrusive symptoms and flashbacks, such as certain dates, colors, a train whistle, certain dog species, all consistent with prior observations. She continued to have variable internal communication with self states during the interview. In the Doris state, Ms. Neely complained about autobiographical memory deficits ascribed to the "3-day coma," although no memory deficit was present in other self states. As Doris, she continued to hear the voice saying, "move on," "don't answer that question," "we'll answer that later." She asked the voice, "what do you know that I don't know?" then became confused.

The defense expert portrayed Ms. Neely as a virtual DID feral child: completely ungovernable, chaotic, and without "coherence" because, in his view, she never had proper treatment. Based on the record, Ms. Neely actually had over 20 years of treatment, some reasonably good - including the work by the dedicated Ms. Brown in a very difficult situation. In several treatments, including the most recent one, despite Ms. Neely's problems, therapists made Herculean efforts to assist her with safety, stabilization, countering regression, and supporting more effective internal communication, collaboration, and coordination among self states. In my interviews, Ms. Neely gave a past history, including trauma history, essentially consistent with the records and reports of prior providers. She described and displayed the same cohort of self states, with the same attributes, as described in all prior medical records and in accounts of past providers. Also, consistently as Doris, she recalled the sequence of events on the day of her arrest consistent with all prior interviews.

In describing her relationship with Ms. Brown, Ms. Neely spoke of her in a covertly aggrieved tone, implying that she, 
Ms. Neely, had done nothing wrong, but that Ms. Brown was in the wrong for "accusing me" of setting the fire at her home. When we later returned to discussing the situation with Ms. Brown and I mentioned that, on the defense expert's video, she had reported calling Ms. Brown, "Mommy," Ms. Neely expressed surprise and denied this.

Suddenly, she began to shake, tremble, moan, hold her head, cover her eyes, and shake her legs rapidly. She stopped these movements, looked up with a terrified stare, and, in a childlike voice, began talking about not being able to "go see Mommy no more." She identified herself as "Sonny," and in a stuttering voice - child self states sometimes present with quasi-childlike speech-perseverated about "Mommy" and how "we be bad. Not go see Mommy anymore."

In the state hospital, emergence of the Sonny state led to a cascade of switching followed by a dyscontrol episode and termination of the interview-just when the interviewer was starting to inquire about Ms. Neely's state of mind at the time of the arson. The defense expert cited the sudden, seemingly unpredictable and intractable emergence of "Sonny" as indicative of Ms. Neely's uncontrollable PTSD symptoms. However, these disruptions occurred when he inquired about Ms. Neely's mental state during the alleged crimes, not randomly. Here, the switch to the Sonny self state had a clear prompt: the question about the complex issue of calling a therapist "Mommy," which Ms. Neely wanted to disavow, as it indicated her attachment to Ms. Brown.

Often, DID individuals report consciously "sending out" a child state to deflect from a difficult topic and appease the interviewer. DID individuals describe learning to be as "little" and inoffensive as possible when endangered by childhood perpetrators, learning not to fight back, as attempts at fight or flight usually resulted in "getting hurt worse." In clinical work with DID, when a DID patient feels threatened by, or is fearful of, the therapist or of a topic in therapy, shifting to a child state is often an attempt to change the subject. Experienced therapists usually confront the patient about this and educate the patient about the developmental impact of role reversals of adults and children. Most experienced DID therapists do not spend much time interacting with child self states, finding therapy to be more effective if one works preferentially with the states that actually have control functions, which typically are angry, violent, subjectively persecutory, seemingly "bad" self states. I surmised that the appearance of "Sonny" had a dual meaning. It was an attempt to deflect from a topic indicating disavowed distress at losing Ms. Brown. The child state embodied the thwarted dependence and loss of "Mommy." At the same time, as in the state hospital and the defense expert's interview, perseverating, disoriented child states would prevent any further inquiry of a topic potentially related to the motive for an arson at Ms. Brown's home.

After interacting with the self state Sonny for a few minutes, I used a technique from clinical work with DID to attempt to retrieve a more functional state. I explained to "Sonny" that "this is a grown-up conversation" and asked whether "he" would agree to "step back" and "perhaps go to sleep in a peaceful, quiet place inside the mind" so I could continue to talk to a "grown-up." Sonny agreed that as I counted from 1 to 3 , he would "take 3 giant steps back within the mind and find a peaceful quiet place to sleep." As I counted, Ms. Neely responded rapidly and completely, stretching out her arms and putting her head down on them, as would an exhausted child.

Using this clinical intervention also helped in assessing how readily Ms. Neely's dysfunctional switching behaviors could be made more manageable and evaluating her innate hypnotizability (International Society for the Study of Dissociation et al., 2011; Kluft, 2012). DID individuals have the highest hypnotic capacity of any clinical group (Frischholz, Lipman, Braun, \& Sachs, 1992; Kluft, 1992). A common, erroneous idea is that hypnosis is used primarily for "memory recovery" in DID therapy (American Society of Clinical Hypnosis Committee on Hypnosis and Memory, 1994; Brown, Scheflin, \& Whitfield, 1999; Kluft, 2012). In the vast preponderance of situations, hypnosis in DID is used for symptom management, containment, grounding, etc. Far from using hypnosis for unearthing "repressed memories," in work on traumatic memories in DID, hypnotic techniques are used to moderate the impact of overwhelming PTSD flashbacks: disorganizing, disorienting, posttraumatic auditory, visual, tactile, olfactory, gustatory, somatic, and/or somatosensory intrusions (Brand, Loewenstein, \& Spiegel, 2014; International Society for the Study of Dissociation et al., 2011). Experts point out that, due to the naturalistic occurrence of spontaneous auto-hypnotic phenomena in DID, no treatment of DID occurs without "hypnosis" (International Society for the Study of Dissociation et al., 2011; Kluft, 2012).

However, despite the high hypnotizability, DID patients can readily resist or rapidly come out of a trance for a variety of psychodynamic and trauma-based reasons. If Ms. Neely had chosen not to respond, she would most assuredly have found a way to further disrupt the interview. Momentarily, without any physical problems, Ms. Neely raised her head again, sat up, blew her nose, and with better eye contact, straighter posture, and a much deeper voice identified herself as "Jeffrey," stating, "I've been waiting to talk to you for 3 days."

In this state, Ms. Neely spoke with me for about $2 \mathrm{~h}$, calmly, cogently, without dissociative overlap or interference or intrusive PTSD symptoms. In the Jeffrey state, Ms. Neely talked at length about her childhood history, including abuse. As Jeffrey, Ms. Neely described being able to "walk around" without difficulty. Ms. Neely talked at length about the details of the exorcistic therapy, including attempts to expel demons and in particular the futile attempts to exorcize the Jeffrey state 
qua "Satan, Lucifer." Later, Mr. Neely gave a history of that period that was consistent with "Jeffrey's" description. Some of the therapy history was also confirmed by the therapist with whom Ms. Neely worked subsequently, who reportedly reported the case to the state licensing board.

In the Jeffrey state, Ms. Neely described the reported rape prior to the end of her treatment with Ms. Brown: “... [It] happened to Anne, Dorrie and another kid [child state]." As Jeffrey, she was able to describe how destabilizing this event had been. Her description is consistent with that of other DID patients recounting the impact of an adult sexual assault. During this description, the Jeffrey state remained grounded, spoke with appropriate affect, and did not display any intrusive symptoms or signs of posttraumatic reactivity.

As Jeffery, she began to hint at talking with me about the events on the day of the fires. She stated that Red would have to be "the one to talk about it." Relatively soon afterwards, the Jeffrey state reported that "it's time for me to go back inside." With a brief counting induction, I assisted the return of the Doris state, who was concerned that "Dorrie was pushing to come out," possibly as a delayed, posttraumatic reaction to discussion of the reported rape. Again, I was easily able to help the Dorrie state "step back" and go into a state of subjective sleep, calming Ms. Neely. This dynamic is common in DID. Self states that experience themselves as disconnected from emotions engendered by traumatic memories can talk about traumatic events in matter-of-fact terms, whereas others subjectively "hold" the emotional content. As discussed above, the PET and fMRI studies of Reinders et al. (2014, 2016) demonstrate different brain activation patterns in self states that experience trauma as autobiographical memory, compared with those who do not. These studies delineate what may be a neurobiological substrate for this clinical phenomenon.

I was not surprised that a traumatized self state, Dorrie, would be activated by the discussion and "push forward." However, I was struck by how easily and completely Ms. Neely responded to hypnotic containment techniques and that the Dorrie state - usually portrayed as an ineluctably emergent force - could so easily be contained. This indicated that Ms. Neely had considerably more control, though surely not total control, over switching behaviors, even when intense posttraumatic reactivity appeared to be intruding.

Later that day, I interviewed the patient's husband and son for about $2 \mathrm{~h}$. Mr. Neely minimized Ms. Neely's history of antisocial behavior, deflecting the blame onto past therapists, misunderstandings, overreactions, etc. Neither reported any history of severe head injury. However, they described that the memory loss occurred during a time when Ms. Neely was under severe stress, having to manage the family and children while her husband's travels for work had escalated. They showed me one of Ms. Neely's journals from that period. Immediately after the onset of the amnesia, she had written in stylized, quasi-childish block print, “... no member people/ places man name [Mr. Neely] say my husband take me to emrgcey (sic) room..." The handwriting and spelling in the journal became more adult over a 3-year period. Overall, the totality of the data indicated a classic scenario of sudden loss of Ms. Neely's entire autobiographical memory-an episode of generalized dissociative amnesia (GDA), not a cognitive disorder. GDA usually occurs when the person suffers massive stress or overwhelming conflicts (Kritchevsky, Chang, \& Squire, 2004; Loewenstein, 2014; Staniloiu \& Markowitsch, 2014; Staniloiu, Markowitsch, \& Kordon, 2018). Usually, in DID, GDA results from the creation of a "new," completely amnestic self-state, to attempt to totally forget the conflicts. The issues that lead to GDA are usually extreme, and often are associated with intense suicidal preoccupations. Thus, in GDA, the loss of personal history and identity frequently represents a symbolic suicide (Loewenstein et al., 2017; Staniloiu $\&$ Markowitsch, 2014). Successful suicide has been reported when too rapid therapeutic attempts have been made to lyse the GDA (Takahashi, 1988).

The next day, I met with Ms. Neely for approximately $8 \mathrm{~h}$. Initially, she switched from the Doris state to the Anne state. In the Anne state, she described "listening to everything" that had been discussed. Many DID individuals describe self states that are aware of most or all of what is occurring, with better episodic memory than endorsed by other self states. As Anne, Ms. Neely stated directly that it would be important to discuss the witnessed fire-setting: "It's good, positive, important...So that the courts will have all the information, we can move on with this, decisions will be made." Then she switched seamlessly to Jeffrey, expressing uncertainty about the legal implications of discussing with me anything further about the fires. I suggested that Ms. Neely, as Jeffrey, call her attorney to discuss this, and arranged with the hospital staff to allow her to do so. As the Jeffrey state, Ms. Neely returned affirming that her attorney gave the go-ahead to talk about the fires.

She switched back to the Anne state. As Anne, she spoke evasively when queried about fire-setting and related activities, such as the past bomb threat, but circumstantially about her history of arrests, generally blaming other people, exculpating "Doris". When I attempted to explore a history of firesetting, Ms. Neely initially denied setting fires but then hinted that she "might" have set fires, but never "to hurt anybody." She began to talk about a long-standing fantasy of murdering her parents by immolating them while they slept in their bedroom, making sure only they were in the house, and ensuring the fire was set in such a way to prevent their escape. She described it as a vivid image that had been in her mind since adolescence. She states that the violent Red state most intensely experienced this fantasy.

After a break, Ms. Neely returned displaying the characteristics of the Doris state. Then she experienced a violent switch, with the emergence of an apparently male child state, self- 
identified as "Billy." In a stammering, childlike voice, Ms. Neely described the morning of the fire-setting and a "struggle" between the Billy state and other states about doing something "bad." She reported that, as Billy, while she was still in therapy with Ms. Brown, Ms. Neely would tell Ms. Brown about potential suicidal, self-destructive and dangerous behavior to get help with maintaining safety. Initially, the Billy state appeared to be referencing the account of following the man who reportedly raped her, with the idea of wreaking vengeance on him. As Billy, Ms. Neely continued to talk about an internal struggle about "taking care" of this man "who had hurt Anne" and that it was "wrong," but "Red said will end the pain, will fix everything." After talking for some time as Billie, Ms. Neely switched again.

She began to talk with a masculine voice similar to that of the Jeffrey state and self-identified as Red, saying, "I want to set the record straight." As Red, Ms. Neely graphically described some of the sadistic sexual abuse reportedly experienced by Ms. Neely at the hands of her father, including his involving dogs in the abuse. She admitted to killing the dogs. "I knew enough to know it's not right to kill the dog... it's not the dog's fault," ... but, "as long as it was on the property, he [father] was going to use it." Eventually, as Red, she stated, "it's gonna fuckin' come out sooner or later. People will put the pieces together. Yes, I did go to this man's house ..." As Red, Ms. Neely first said that she had followed "a man who hurt us"- - presumably the reported rapist. She shifted into talking about details of reported horrific, sadistic rape by her father in childhood and simmering revenge fantasies. Again, she did not enter a flashback state, but bitterly and angrily described her humiliation and rage.

In her descriptions, Ms. Neely appeared to be shifting back and forth from the recent rape to the reported childhood assaults. At one point, we were interrupted and she was required to return briefly to her inpatient unit. Ms. Neely rapidly switched back to the Anne state to go to her ward, returning about 30 minutes later. Then she shifted rapidly back to the Red state. Without missing a beat, she continued to describe "following the man" but seemingly thinking she was in her parents' house. When I asked what the parents were doing in the current place and year, Ms. Neely stated, "it's not [year], it's 1969 or something." I asked clarifying questions, such as how she thought she was killing her parents while living in a completely different place, in the current year. Ms. Neely as Red responded irritably and evasively to this kind of query. She continued describing the apparent fantasy of wanting to find her father asleep in his bedroom and setting it on fire to immolate him. Then she described confusion. It wasn't the right house. The bedroom was not where it was supposed to be. She, as Red, was setting towels and pot holders on fire on the stove. She described setting a fire on the living room couch, including recounting the specific lighter and tinder that she used. She returned to the beginning of the event and described opening the door to the house, calling out, no one answering, thinking "this is going to work!" Ms. Neely as Red described every specific element of the events in the witnessed fire: the specific lighter she used, the appearance of the young man grabbing her left arm, confusion about not being in the right house - how could this person be here? She expected her mother or father, etc. Each element of the witnessed crime was specifically linked to an element of the putative revenge fantasy/flashback of murdering Ms. Neely's parents by burning them to death.

She admitted saying, "I'm sick!" when the young man shouted, "What are you doing?" When asked about it, she said, "I don't know, it was the first thing that came to mind... we should have stayed in therapy." On further questioning, Ms. Neely could describe in detail exactly how the young man held her left arm, pulling her back into the kitchen, then letting her go to call 911. Ms. Neely describes getting out the door and into the truck and escaping. At a certain point in the drive, she reported, Red "left" and "someone else drove home." During the long description of the fire, Ms. Neely briefly said she was "sorry to that young boy"- the only acknowledgment of concern about anyone but herself in 20 hours of interviews.

I asked about the fire at Ms. Brown's house. As Red, Ms. Neely volubly denied any negative feelings about Ms. Brown. Then, she gave a long digressive discussion about the timing of the fire, claiming that she could not have set it, since she falsely insisted that it happened after she had been brought to police headquarters. She contended that the paint fragments on the garage door could not have come from her truck, despite being so identified by the state forensic laboratory.

As Red, Ms. Neely discussed subsequently talking to her lawyer about what she had just told me. She cogently described the possible outcomes of the case, which were either jail or a forensic psychiatric hospital. She described the possible impact of prison on various self states. She referenced several discussions with her lawyer and husband about the case, the evidence, the paint fragments, etc. She quoted her lawyer as telling her "...they have an open and shut case ... about the fire where the young man there is holding you. You're seen there, the license plate [is seen] there. OK. That's happened. Here [fire at Ms. Brown's home] you have nothing! You don't have nobody, anything [on that charge], they got nothing!"

At the conclusion of the interview, Ms. Neely switched back to the Anne state, who readily referenced the prior bomb threat case, though disavowing guilt. She talked about the Doris state and the difficulty "she" would have dealing with the information just shared by Red, the possibility of prison versus a psychiatric hospital, that the latter was the hoped-for outcome. She concluded by saying, "Everything's coming down to competency, [to the] courtroom. Deciding where [to place] her." 


\section{Diagnosis (DSM-IV-TR) Axis I}

Dissociative identity disorder (300.14)

Complicated by single episode generalized dissociative amnesia

Posttraumatic stress disorder (309.81)

Major depressive disorder, non-psychotic, recurrent (296.33)

Conversion disorder (300.11) with motor and sensory symptoms

Somatoform pain disorder (307.89), chronic, site lower back (724.2)

Malingering (V65.2) with exaggeration of symptoms of dissociative identity disorder

Malingering (V65.2) symptoms of amnestic disorder secondary to general medical condition

Malingering (V65.2) with exaggeration of physical and somatoform symptoms

\section{Axis II}

Personality disorder NOS (301.9) [mixed personality disorder] with severe antisocial and paranoid features, as well as avoidant features

\section{Competence}

Ms. Neely had adequate factual and rational understanding of the charges against her to rationally assist her attorney with her case.

\section{Insanity}

Witnessed Arson

At the time of the criminal conduct, Ms. Neely had adequate capacity to appreciate the criminality of her conduct and to conform her conduct to the requirements of the law.

\section{Unwitnessed Arson}

Ms. Neely insisted she did not commit this crime. Thus, there was insufficient information to assess her mental state for this crime. However, there were no data to suggest she would have had a different state of mind during commission of the arson at the home of Ms. Brown than at the time of the witnessed arson. Thus, there was no evidence to make the affirmative case that Ms. Neely was insane at the time of commission of this crime than she was during the prior one. Under the laws of her state, it is the duty of the defense to show the preponderance of the evidence favors a finding of NGRI.

\section{Conclusions}

Diagnosis Ms. Neely met DSM-IV-TR diagnostic criteria for dissociative identity disorder (DID). She displayed clear-cut switching between two or more alternate personality states as well as dissociative amnesia, including an episode of generalized dissociative amnesia (GDA) that she claimed, and some of her providers believed, was a cognitive disorder related to a severe TBI. Over the years, Ms. Neely's family members, all prior treatment providers, and the psychiatric records describe the same panoply of self states, behaviors, symptoms, and treatment trajectories. These symptom clusters, such as passive influence symptoms and "hearing" the personified voices of DID self states within the mind, are pathognomonic for DID (Loewenstein, 1991a).

Ms. Neely reported chronic complex amnesia symptoms including disremembered behavior (including positive behavior), subjective time loss, fugues, appearance of unexplained possessions, and inexplicable changes in handwriting and physical abilities (e.g., ability to walk without crutches). During the clinical interview, she showed spontaneous trance behavior and related auto-hypnotic phenomena, as well as movements and behaviors typical of highly dissociative individuals. In addition, she met DSM-IV-TR diagnostic criteria for PTSD and at least two somatoform disorders, all common DID co-morbidities.

The state hospital staff who observed Ms. Neely for weeks accounted for her behavior as entirely malingered. Her dramatic clinical presentation, symptom variability, bizarre and contradictory responses on standardized assessment measures, and repeated insistence that DID exculpated her from criminal responsibility all were interpreted as malingered. Their observations were completely accurate; Ms. Neely showed behaviors that are classic for malingering (Brand, Webermann, et al., 2016; Coons \& Milstein, 1994; Thomas, 2001).

In reality, both DID and malingered exaggeration of DID symptoms characterized Ms. Neely's psychiatric presentation.

The goal of the malingering was to deliberately be found incompetent to stand trial and to appear so mentally ill as to meet the legal standard of insanity - concepts that, based on her interviews with me, she appeared to understand quite well. When queried directly, Ms. Neely responded with dramatic claims of DID symptoms with frequent "you can't get there from here" responses. She presented herself as naïve to DID treatment, desperately in need of expert help, a vulnerable amnesia victim unable to account for her situation. Ms. Neely presented the self states as independent "people," with total amnesia between them. She appeared to unpredictably switch among child self states; confused, disoriented, dyscontrolled self states; and violent, angry, frightening, even assaultive self states; and she responded with lucid indignation when, in the state hospital, there were consequences for her behavior.

She bewildered her attorney and her forensic examiners by insisting that she had little recall of prior interactions, and was seemingly unable to provide a coherent or understandable account of her mental state at the time of the alleged criminal conduct. She minimized her prior criminal and legal history, ascribing problematic interactions to DID, misunderstandings, or overreactions by past providers. This led her attorney and the defense and the court's first expert to view Ms. Neely as requiring intensive mental health treatment to resolve severe symptoms of an overwhelming dissociative disorder, with hopes that 
Ms. Neely will finally get "the treatment she needs." From a legal perspective, the treatment would be to restore competence to stand trial. In my opinion, Ms. Neely believed she would enter a specialized treatment facility and game the situation from there, having seen how easy it can be to con mental health providers into being sympathetic to her, at least initially. She typically left hospitals after brief admissions, including the specialty trauma/dissociative disorder programs.

However, malingered exaggeration of DID became apparent when Ms. Neely was queried as a self-state system. It became clear that perspicaciously vigilant self states were closely monitoring the interviews and calibrating her responses. Once engaged in the interview process, Ms. Neely was able to switch voluntarily among several self states. She maintained the presence of cogent, aware, and focused self states for hours during stressful interviews on successive days. This included discussion of past alleged traumas and details of her alleged behavior and mental state during criminal conduct.

Ms. Neely met DSM-IV-TR diagnostic criteria for conversion disorder, with motor and sensory symptoms; somatoform pain disorder, chronic, site lower back (724.2). In addition to meeting criteria for malingering with exaggeration of symptoms of dissociative identity disorder, Ms. Neely also met criteria for malingering symptoms of amnestic disorder secondary to general medical condition (TBI), and for exaggeration of physical symptoms.

When assessed at the level of the "whole human being," Ms. Neely met clear DSM-IV-TR criteria for a mixed personality disorder (personality disorder NOS) with antisocial, paranoid, and avoidant traits. With respect to antisocial personality disorder features, Ms. Neely exhibited past behaviors that resulted in arrest, deceitfulness, and striking lack of remorse for current and past criminal behavior. The lack of remorse was evident throughout every interview with every examiner. Ms. Neely repeatedly painted herself as wronged by Ms. Brown for suspecting her of committing arson at Ms. Brown's home. After about 18 hours of interviews, Ms. Neely made a brief apology to the man who witnessed the arson. This was rapidly replaced by concerns about Ms. Neely's situation and what would be of "help" to her. Ms. Neely never asked about the well-being of any of the alleged victims or expressed regret for their distress or suffering, or damage to their property. Ms. Neely denied culpability for the fire at Ms. Brown's home. She never expressed any empathy, regret, or sadness about Ms. Brown's losses and the deaths of the pets. Ms. Neely's focus was entirely on herself in her repeated denials of culpability for the alleged crimes.

In addition, across all interviews, Ms. Neely displayed consistent paranoid personality traits. These included deep distrust and suspiciousness of being tricked, railroaded, lied to, and exploited. Often, this was her only explanation for events with which she was displeased. She appeared to harbor deep grudges and resentment of those whom she perceived had wronged her and had a history of acting vengefully against them. When Ms. Neely realized that she was not going to be referred to a specialized trauma program, should she be found incompetent or NGRI, she began to blame her dedicated attorney and the defense expert for misleading her.

Competence As other examiners found, when one attempted to do a standard competency interview with Ms. Neely, one got a whirlwind of disjointed and bizarre responses. However, when the interview was focused on the self-state system, Ms. Neely showed abundantly clear, comprehensive knowledge of the legal charges, the court system, the basis for a finding of CTS and NGRI, the possible outcomes of the case, what she needed to discuss with her attorney, etc. In the Red state, she even finished with a clear, gangster-like "they got nothin' on me" defense of the unwitnessed arson charges. She spoke at length about needing to talk with her attorney and her husband about strategies that would lead to hospitalization, not to prison. If necessary, she agreed to testify in court in one of these more grounded states. She was able to maintain state stability for hours during my interviews and gave clear evidence that important information about her legal situation - and all other matters - was shared among states. These self states knew a great deal about what was occurring, but, when it appeared convenient, chose to look as disturbed as possible, often by "sending out" the Doris state or confused child states, and engendered rapid dysfunctional switching in order to appear unpredictable, helplessly bewildered, and incapable of responding coherently. The state hospital staff observed both patterns. Depending on what seemed most advantageous, Ms. Neely could rapidly shift from apparent amnestic, child-like confusion to cogent, hypervigilant, hypermnesic truculence.

\section{Sanity Witnessed Burglary and Arson}

Ms. Neely discussed her behavior and motivations for this event in a malingered flashback. In DID, actual flashbacks are disorganizing, distracting, and overwhelming. These can range from disruptive with partial awareness of current circumstances to complete loss of awareness of the present time and place, termed loss of "duality" (Kluft, 2013). In these states, the DID individual may appear highly agitated but more commonly appears frozen in a trance state and may even become mute and unresponsive. The person may close their eyes or stare off into space and will acknowledge seeing hallucinatory, flashback images. If the person can talk, they commonly report information in fragmentary, disjointed ways, not a coherent narrative.

It may take considerable therapeutic effort to help the person out of flashback and into a more grounded state. Subsequently, the person will often describe partial or complete amnesia for the flashback, and, even when grounded, may describe ongoing partial flashback symptoms and posttraumatic distress needing clinical attention. 
As the Jeffrey, Anne, and Red states, Ms. Neely described the events of the arson in a way that, in my opinion, she hoped I would believe was a flashback. It was like no flashback I have ever encountered. Every detail of the witnessed fire, including the specific arm that the victim grabbed, was accounted for-precisely. She described secondary process observations such as surprise, disorientation, confusion, and distress at realizing she was in the "wrong house" and the "wrong person" was there. Ms. Neely interrupted the interview for approximately $30 \mathrm{~min}$ by switching to a self state that would interact with the hospital staff. Then, on her return, she rapidly, voluntarily switched back to Red and continued the narrative where she had left off. She reported the entire interaction with the man in the house, including responding, "I'm sick," and calmly walking to her truck when the man let go of her arm. This melded with the fantasy - which may well be an actual one - in the pseudo-flashback of thinking she was immolating her parents. Even if every "flashback" element of this description is taken at face value, Ms. Neely clearly describes knowing the difference between right and wrong and the ability to plan, to delay, and to escape. In addition, as with the account to the defense expert, she began her story implying that she chose the house that was the target of her arson by following her recent alleged rapist, with the goal of avenging the rape ("the man who hurt Anne"). In my opinion, this was meant to be a back-up exculpatory trauma narrative. Here, she counted on the "sympathetic" trauma-focused interviewer responding as Ms. Brown did to the shoplifting charge: testifying that this "understandable" dissociative process "caused" the crime.

\section{Unwitnessed Arson and Burglary at Ms. Brown's Home}

I agreed with the other experts that one cannot directly assess the question of NGRI for this crime, due to Ms. Neely's denials and evasions. However, given the description of her mental state in the other crime, and her "you got nothing on me" response, there was no evidence that the defense could meet its burden of proving NGRI.

I appended an additional conclusion to my report to the court. I hypothesized that if one viewed Ms. Neely as coordinated, crafty, and manipulative instead of as disorganized, amnestic, and lacking psychological "coherence," one could discern "a rational motive" for both arsons - and even the third arson of that morning, for which no other suspect ever emerged. Had Ms. Neely committed a single arson at her former therapist's home, she would be a logical suspect: a disgruntled former patient with a known history of committing arson. Additionally, one could see a clear motive for this crime: jealousy, envy, revenge for abandonment for ending treatment and rejecting Ms. Neely repeatedly afterwards. Ms. Brown had everything Ms. Neely wanted but did not have: a happy, comfortable home life, a loving husband, a good career, a lovely home with a farm attached, horses, dogs. We know Ms. Neely acted vengefully in the past, particularly in the context of rejection: tearing out the wires of her husband's car before they married; vandalizing a former therapist's car and garage; stalking this therapist after therapy ended, even attempting to evade a restraining order. Ms. Brown reported feeling stalked by Ms. Neely. Ms. Neely knew where Ms. Brown lived, where she worked, knew her daily routines. She would leave frequent voice mail messages or send emails with information that she had gathered about Ms. Brown, who, due to this, eventually stopped listening to voice mail altogether.

In her accounts to the defense expert in the Jeffrey state, and to me in the Jeffrey, Billy and Red self states, Ms. Neely implied that the witnessed fire was set either in a dissociated attempt to get revenge on the man who allegedly raped her earlier in the year, and/or in a kind of dissociated flashback, believing that she was murdering her parents in 1969. If taken at face value, these explanations are difficult to align with the idea of a crime of revenge against Ms. Brown. However, if multiple, seemingly unconnected arsons occurred on the same day, it would appear that the arsonist was not targeting anyone in particular. The crimes would more readily be seen as random. Ms. Neely would seem a less likely suspect and could more plausibly deny her role in any of the fires. This model fits with testimony of witnesses who identified Ms. Neely as the woman they noticed knocking, apparently randomly, on doors at other dwellings on the morning of the arsons. They described she appeared flustered when someone answered their door. Even if she were caught, Ms. Neely may have hypothesized, she could use the DID excuse for exculpation as she had done for other charges in the past. She could promulgate "crazy" - but sympathetic "trauma-based"- motives such as being in a flashback or an altered state, revenge against an alleged perpetrator, revenge against her abusive parents. She could present herself as completely dissociated, unable to manage a simple conversation with her attorney, switching uncontrollably. Certainly, she would be found incompetent to stand trial and not guilty by reason of insanity.

I testified to these opinions at a competency hearing. Ms. Neely observed me carefully and spoke up several times from the defense table attempting to correct my testimony - at one point accurately identifying a mistake that I then rectified. I noted to the court that this was further support for my opinions: that she was cogently tracking what was occurring in court and had excellent recall of her interviews with me. Subsequently, with an external "trigger," she switched to the Sonny state and appeared to go to sleep with her head on her arms. Her attorney and husband helped her from the courtroom.

\section{Disposition}

Ms. Neely pled no contest to all charges. She was sentenced to $5-15$ years in prison, with all but 5 years suspended. With 
about three years of incarceration behind her, she likely would have had to serve only another 2 years. However, the state's attorney let me know that, while in prison, Ms. Neely had engaged in dishonest and disruptive behavior in defiance of her plea agreement, putting her release in jeopardy.

\section{Aftermath}

After the case concluded, I belatedly was sent a copy of the arrest report for the shoplifting charge. Ms. Neely entered the Walmart store and picked up clothing and shoes from several departments and placed them in her shopping cart. A store security officer watched Ms. Neely enter a fitting room with her cart, where she remained for about 45 minutes. The officer could hear price tickets being ripped and items being placed in a plastic bag. When Ms. Neely left the fitting room, she had a store bag with merchandise on the bottom of her shopping cart and was wearing a pair of new sneakers she had brought to the fitting room. In the fitting room, the officer found multiple price tags on the floor and a pair of old shoes in the sneaker box. Ms. Neely paid for some items but exited the store without paying for the sneakers, the merchandise in the bag, or the stolen clothing she was wearing. She was confronted by the security officer and subsequently arrested. Ms. Neely called her husband, who came to pick her up and helped bring herbraces and crutches and all- to be booked. Ms. Neely appeared quite anxious, and after a number of minutes, began rocking, crying out, shaking, and bumping her head lightly on the wall. This worsened when the officer approached, and he was fearful of a violent incident. However, Mr. Neely calmed Ms. Neely throughout the booking process. Mr. Neely explained to the officer that his wife suffered from PTSD and had "abuse issues" around men.

There was no evidence that she had urinated on her clothes.

\section{Discussion}

The assessment of CTS, NGRI/NCR in criminal proceedings with putative DID defendants invariably will be complex. The evaluation of Ms. Neely demonstrates a conceptually sound way to approach these cases and avoid the trap of reifying self states. This is particularly important around the issue of responsibility for behavior. A major or sole focus on the presentational differences among self states leads to a slippery slope of attempting to account for behavior as if the DID individual contained separate people, acting more-or-less independently, (Armstrong, 2001; Behnke, 1997a, 1997b; Saks, 1997; Sinnott-Armstrong \& Behneke, 2001). The Discrete Behavioral State model of DID as an alternative developmental pathway can help forensic examiners, as well as clinicians, more readily conceptualize DID as an adaptive psychological system in a single human being. The secondary, subjective structuring of self states is only limited by human imagination. Clinical and forensic evaluation always should assess DID in terms of the individual self states, the self-state-system, and the mind as a whole.

In many cases, it is helpful to complete a comprehensive psychological assessment battery designed to evaluate DID, feigned DID, and DID with feigning (Brand, Schielke, \& Brams, 2017; Brand, Schielke, Brams, et al., 2017). Researchers continue to evaluate the reliability of standard clinical and forensic measures to assist the assessment of DID in both contexts (Brand, Webermann, et al., 2016; Brand, Webermann, et al., 2019; Palermo \& Brand, 2019). Defendants may not cooperate fully with assessment, however, as was the case with Ms. Neely.

\section{Control Over Behavior in DID}

In my assessment, Ms. Neely was shown to be a cold, calculating, manipulative, self-centered, criminal human being with an unexpected amount of control over her behavior, including control over symptoms of her disorder. She was good at manipulating mental health professionals, especially those disposed to sympathy for trauma survivors. Are all DID individuals able to control themselves in this way? Many DID individuals, even without treatment, have the ability to observe and control their behavior - up to a point. Ultimately, posttraumatic and dissociative responses override the controls or create self-defeating and damaging circumstances for the DID individual. There are a number of variables that bear on this question. These include person-specific variables such as their level of function in school, work, and relationships. The functioning of DID individuals can range from chronically and persistently mentally ill to very high overall functioning. There is a range of treatment response from individuals requiring frequent attention at more restricted levels of care to individuals who rapidly respond to outpatient treatment (Brand, Classen, McNary, \& Zaveri, 2009; Kluft, 1994b; Loewenstein, 1994). The extent of clinical decompensation in DID is a factor, as severely dysregulated PTSD and dissociative symptoms are associated with poorer behavioral control and reality testing (Ross et al., 2014; Sar et al., 2017a). Many DID patients spend years misdiagnosed in the mental health system (Brand, Schielke, et al., 2019). By the time these patients are properly diagnosed, many have suffered major iatrogenic damage and psychosocial loss and are massively demoralized and overwhelmed (Coons, 1989). Context also affects behavioral control. As Armstrong (2001) describes, the examiner needs to evaluate whether the problematic behavior occurred impulsively, as with her subject, Mr. Woods, or whether, as with Ms. Neely, careful planning can be discerned for the behavior. 
The capacity for control of dissociative and posttraumatic symptoms improves with appropriate treatment that emphasizes coordination, collaboration, and cooperation among self states and teaches techniques for managing dissociative and posttraumatic symptoms. Based on the record, with one major exception, Ms. Neely's treatment was focused on managing DID symptoms. With treatment, she appears to have learned and strengthened skills that assisted her to better control switching and posttraumatic activation, even when discussing highly distressing trauma memories, with congruent emotions. Paradoxically, the resilience factors found in DID may actually have led Ms. Neely to be a more successful criminal. Ms. Neely had the capacity to test reality and self-monitor, which she used manipulatively; ability to plan and delay; some capacity for empathy and attachment, though very disturbed attachment, both of which she also could use manipulatively.

It is possible that the resilience in DID could allow some sociopathic DID individuals to be more successful criminals. The author has encountered DID individuals who were successful in criminal sub-cultures, who experienced severe dissociative and posttraumatic symptoms that ultimately disabled them-from their criminal careers.

The state hospital evaluation questioned whether Ms. Neely's DID was the result of "suggestive" therapies involving hypnosis. In fact, their own observations documented Ms. Neely's imperviousness to outside influence. In the descriptions of the exorcistic therapy where Ms. Neely was apparently highly dependent on her therapist as the "mommy" she had always wished for, she consistently refused to endorse a history of "Satanic Ritual Abuse" or that the Jeffrey state was demonic. When I inquired about this, she again denied such a history. Studies of various suggestibility paradigms in dissociative individuals show quite low suggestibility (Dalenberg, Brand, et al., 2012; Kluemper \& Dalenberg, 2014). Indeed, review of the clinical literature and clinical experience shows that, in general, DID individuals are far more stuck than suggestible. However, due to developmental, dissociative, and posttraumatic factors, they are often too easily influenced by those who would revictimize or exploit them (Myrick et al., 2013).

Ms. Neely appears to have learned that many trauma therapists will minimize or rationalize even antisocial behavior in DID individuals, if a compellingly sympathetic, trauma/ dissociation-based story is delivered, e.g., the shoplifting charge. In promulgating her pseudo-flashback story of the witnessed arson, Ms. Neely appeared to be counting on the suggestibility of the evaluators to buy into the idea of either her righteous dissociative pursuit of a "bad guy" and/or the description she layered on top of a dissociatively disoriented flashback where she gets revenge on her "bad guy" family. With this, combined with presenting herself as a symptomatically inchoate, jumbled, dissociatively symptomatic disaster, she appeared convinced that she could beat the charges and be found incompetent and legally insane. However, we should not forget that, whatever the specifics of her trauma history, Ms. Neely was a seriously damaged, mentally ill woman who, at times, was overwhelmed by major dissociative and posttraumatic symptoms (Vaillant, 1975). Yet, she was shrewdly and sophisticatedly able to manipulate others. At the same time, there were limits to her ability to this. She malingered poor performance on psychological assessment measures, yet wrote cogent marginal comments on some of them. Finally, she was not able to manipulate professionals with a deeper and more nuanced conceptualization of DID.

As in this case - and for all DID individuals - it is crucial to start by conceptualizing responsibility at the level of the whole human being. The whole human being is considered responsible for behavior, even if the behavior is ascribed only to a specific self state or self states, and even if amnesia or involuntariness is claimed. Also, because of dissociative cognitive resilience, many DID individuals clearly can articulate the difference between right and wrong, again, across many self states, both directly and indirectly. The forensic assessment, as in Armstrong's (2001) case of Mr. Woods, should demonstrate how the DID individual's psychopathology, including co-morbid conditions, has caused sufficient impairments to fail the standard for CTS and/or to be judged NGRI/NCR.

Most DID individuals report being treated with profound irresponsibility by those who should have protected them. It is an important treatment principle for DID patients to not excuse, minimize, or rationalize irresponsible, let alone criminal, behavior (Armstrong, 2001; Beahrs, 1994; International Society for the Study of Dissociation et al., 2011; Kluft, 1993). In clinical work, one can help the patient understand problematic behavior, yet make sure that the person is consistently confronted about dishonesty, abusiveness towards others, and antisocial behavior. In DID and other traumabased disorders, it is crucial to understand that explanations are not excuses. In particular, child neglect or maltreatment by DID individuals cannot be tolerated; the abuse must be reported to child protective services. Optimally, the DID individual should both accept responsibility for problematic behavior, and also attempt to understand what factors led to it, in order to not repeat it. In both clinical and forensic work with DID, it is critical to remember:

Human beings behave. Self states do not. Explanations are not excuses.

Open Access This article is licensed under a Creative Commons Attribution 4.0 International License, which permits use, sharing, adaptation, distribution and reproduction in any medium or format, as long as you give appropriate credit to the original author(s) and the source, provide a link to the Creative Commons licence, and indicate if changes were 
made. The images or other third party material in this article are included in the article's Creative Commons licence, unless indicated otherwise in a credit line to the material. If material is not included in the article's Creative Commons licence and your intended use is not permitted by statutory regulation or exceeds the permitted use, you will need to obtain permission directly from the copyright holder. To view a copy of this licence, visit http://creativecommons.org/licenses/by/4.0/.

\section{References}

Allison, R. B. (1984). Difficulties diagnosing the multiple personality syndrome in a death penalty case. International Journal of Clinical and Experimental Hypnosis, 32(2), 102-117. https://doi. org/10.1080/00207148408416006.

Allison, R. B., \& Schwartz, T. (1999). Minds in many pieces: Revealing the spiritual side of multiple personality disorder. Paso Robles: Cie Publishing Company.

American Association of Psychiatry and the Law. (2015). AAPL practice guidelines for forensic assessment. Journal of the American Academy of Psychiatry and the Law, 43(2), S3-S53.

American Psychiatric Association. (1980). Diagnostic and statistical manual of mental disorders (3rd ed.). Washington D.C.: American Psychiatric Press.

American Psychiatric Association. (1994). Diagnostic and statistical manual of mental disorders (4th ed.). DSM-IV Washington D.C.: American Psychiatric Press.

American Psychiatric Association. (2000). Diagnostic and statistical manual of mental disorders DSM-IV-TR (Text Revision). Washington D.C.: American Psychiatric Press.

American Psychiatric Association. (2013). Diagnostic and statistical manual of mental disorders DSM-5. Washington D.C.: American Psychiatric Press.

American Society of Clinical Hypnosis Committee on Hypnosis and Memory, \& [Hammond, D. C., Garver, R.B., Mutter, C.B., Crasilneck, H.B., Frischholz, E., Gravitz, M., Hibler, N.S., Olson, J., Scheflin, A., Spiegel, H., \& Wester, W.]. (1994). Guidelines for clinicians working with hypnosis and memory \& guidelines for the conduct of forensic hypnosis interviews. Des Plaines, Il: American Society of Clinical Hypnosis.

Anfang, S. A., Gold, L. H., \& Meyer, D. J. (2018). AAPL practice resource for the forensic evaluation of psychiatric disability. Journal of the American Academy of Psychiatry and the Law Online, 46(1 Supplement), S2-S47 http://jaapl.org/content/jaap1/46/1 Supplement/S2.full.pdf.

Armstrong, J., Putnam, F. W., Carlson, E., Libero, D., \& Smith, S. (1997). Development and validation of a measure of adolescent dissociation: The adolescent dissociative experience scale. Journal of Nervous and Mental Disease, 185, 491-497.

Armstrong, J. G. (1991). The psychological organization of multiple personality disordered patients as revealed in psychological testing. Psychiatric Clinics of North America, 14, 533-546.

Armstrong, J. G. (1994). Reflections on multiple personality disorder as a developmentally complex adaptation. Psychoanalytic Study of the Child, 50, 349-364.

Armstrong, J. G. (2001). The case of Mr. Woods: Psychological contributions to the legal process in defendants with multiple personality/ dissociative identity disorder. Southern California Interdisciplanary Law Journal, 10(2), 205-224.

Armstrong, J. G., Laurenti, M. B., \& Loewenstein, R. J. (1991). Dissociative behaviors checklist-II. Towson: Sheppard and Enoch Pratt Hospital.

Beahrs, J. O. (1994). Dissociative identity disorder: Adaptive deception of self and others. Bulletin of the American Academy of Psychiatry and the Law, 22, 223-237.
Behnke, S. H. (1997a). Assessing the criminal responsibility of individuals with multiple personality disorder: Legal cases, legal theory. Journal of the American Academy of Psychiatry and the Law, 25(3), 391-399.

Behnke, S. H. (1997b). Confusion in the courtroom: How judges have assessed the criminal responsibility of individuals with multiple personality disorder. International Journal of Law and Psychiatry, 20, 293-310.

Bernstein, E. M., \& Putnam, F. W. (1986). Development, reliability, and validity of a dissociation scale. Journal of Nervous and Mental Disease, 174, 727-735.

Berry, K., Varese, F., \& Bucci, S. (2017). Cognitive attachment model of voices: Evidence base and future implications. Frontiers in Psychiatry, 8, 111. https://doi.org/10.3389/fpsyt.2017.00111.

Blair, J. (2002). Man who shot priest in an abuse case wins acquittal. The New York Times, p. 28. Retrieved from https://www.nytimes.com/ 2002/12/17/us/man-who-shot-priest-in-an-abuse-case-winsacquittal.html.

Blank, A. S. (1985). The unconscious flashback to the war in Viet Nam veterans: Clinical mystery, legal defense, and community problem. In S. M. Sonnenberg, A. S. Blank, \& J. A. Talbott (Eds.), The trauma of war: Stress and recovery in Vietnam veterans (pp. 293308). Washington D.C.: American Psychiatric Press.

Boodman, S. G., \& Davis, P. (2003, September 28). VA. doctor's misconduct left trail of broken lives. The Washington Post.

Boon, S., \& Draijer, N. (1993). The differentiation of patients with MPD or DDNOS from patients with cluster B personality disorder. Dissociation, 6, 126-135.

Boon, S., Steele, K., \& van der Hart, O. (2011). Coping with traumarelated dissociation: Skills training for patients and therapists. New York: W.W. Norton \& Company.

Bourget, D., Gagne, P., \& Wood, S. F. (2017). Dissociation: Defining the concept in criminal forensic psychiatry. Journal of the American Academy of Psychiatry and the Law, 45(2), 147-160.

Bourget, D., \& Whitehurst, L. (2007). Amnesia and crime. Journal of the American Academy of Psychiatry and the Law, 35, 469-480.

Bowman, E. S. (1993). Clinical and spiritual effects of exorcism in fifteen patients with multiple personality disorder. Dissocation, 6(4), 222238.

Brand, B., Armstrong, J. A., \& Loewenstein, R. J. (2006). Psychological assessment of patients with dissociative identity disorder. Psychiatric Clinics of North America, 29(1), 145-168.

Brand, B., Armstrong, J. A., Loewenstein, R. J., \& McNary, S. W. (2009). Personality differences on the Rorschach of dissociative identity disorder, borderline personality disorder, and psychotic inpatients. Psychological Trauma: Theory, Research, Practice, and Policy, 1(3), 188-205.

Brand, B. L., Chasson, G. S., Palermo, C. A., Donato, F. M., Rhodes, K. P., \& Voorhees, E. F. (2016). MMPI-2 item endorsements in dissociative identity disorder vs simulators. Journal of the American Academy of Psychiatry and the Law, 44, 63-72.

Brand, B. L., Classen, C. C., McNary, S. W., \& Zaveri, P. (2009). A review of dissociative disorders treatment studies. Journal of Nervous and Mental Disease, 197, 646-654.

Brand, B. L., Dalenberg, C. J., Frewen, P. A., Loewenstein, R. J., Schielke, H. J., Brams, J. S., et al. (2018). Trauma-related dissociation is no fantasy: Addressing the errors of omission and commission in Merckelbach and Patihis (2018). Psychological Injury and Law. https://doi.org/10.1007/s12207-018-9336-8.

Brand, B. L., Loewenstein, R. J., \& Lanius, R. (2014). Treatment of dissociative identity disorder. In G. O. Gabbard (Ed.), Gabbard's treatments of psychiatric disorders (pp. 439-458). Washtington D.C.: American Psychiatric Association Press.

Brand, B. L., Loewenstein, R. J., \& Spiegel, D. (2014). Dispelling myths dissociative identity disorder treatment: An empirically based approach. Psychiatry, 77(2), 169-189. 
Brand, B. L., McNary, S. W., Loewenstein, R. J., Kolos, A., \& Barr, S. (2006). Assessment of genuine and simulated dissociative identity disorder symptoms on the structured interview of reported symptoms. Journal of Trauma and Dissociation, 7(1), 63-85.

Brand, B. L., McNary, S. W., Myrick, A. C., Classen, C. C., Lanius, R., Loewenstein, R. J., et al. (2012). A longitudinal naturalistic study of patients with dissociative disorders treated by community clinicians. Psychological Trauma: Theory, Research, Practice, and Policy, 5(4), 301-308. https://doi.org/10.1037/a0027654.

Brand, B. L., McNary, S. W., Myrick, A. C., Classen, C. C., Lanius, R., Loewenstein, R. J., et al. (2013). A longitudinal naturalistic study of patients with dissociative disorders treated by community clinicians. Psychological Trauma: Theory, Research, Practice, and Policy, 5(4), 301-308. https://doi.org/10.1037/a0027654.

Brand, B. L., Myrick, A. C., Loewenstein, R. J., Classen, C. C., Lanius, R., McNary, S. W., et al. (2011). A survey of practices and recommended treatment interventions among expert therapists treating patients with dissociative identity disorder and dissociative disorder not otherwise specified. Psychological Trauma: Theory, Research, Practice, and Policy. https://doi.org/10.1037/a0026487.

Brand, B. L., Myrick, A. C., Loewenstein, R. J., Classen, C. C., Lanius, R. A., McNary, S. W., et al. (2012). A survey of practices and recommended treatment interventions among expert therapists treating patients with dissociative identity disorder and dissociative disorder not otherwise specified. Psychological Trauma: Theory, Research, Practice, \& Policy, 4(5), 490-500. https://doi.org/10. 1037/a0026487.

Brand, B. L., Sar, V., Stavropoulos, P., Kruger, C., Korzekwa, M., Martinez-Taboas, A., et al. (2016). Separating fact from fiction: An empirical examination of six myths about dissociative identity disorder. Harvard Review of Psychiatry, 24(4), 257-270. https://doi. org/10.1097/HRP.0000000000000100.

Brand, B. L., Schielke, H. J., \& Brams, J. S. (2017). Assisting the courts in understanding and connecting with experiences of disconnection: Addressing trauma-related dissociation as a forensic psychologist, part I. Psychological Injury and Law, 10(4), 283-297. https://doi. org/10.1007/s12207-017-9304-8.

Brand, B. L., Schielke, H. J., Brams, J. S., \& DiComo, R. A. (2017). Assessing trauma-related dissociation in forensic contexts: Addressing trauma-related dissociation as a forensic psychologist, part II. Psychological Injury and Law, 10(4), 298-312. https://doi. org/10.1007/s12207-017-9305-7.

Brand, B. L., Schielke, H. J., Putnam, K. T., Putnam, F. W., Loewenstein, R. J., Myrick, A., et al. (2019). An online educational program for individuals with dissociative disorders and their clinicians: 1-year and 2-year follow-up. Journal of Traumatic Stress, 32, 156-166. https://doi.org/10.1002/jts.22370.

Brand, B. L., Tursich, M., Tzall, D., \& Loewenstein, R. J. (2014). Utility of the SIRS-2 in distinguishing genuine from simulated dissociative identity disorder. Psychological Trauma: Theory, Research, Practice, and Policy, 6(4), 308-317. https://doi.org/10.1037/ a0036064.

Brand, B. L., Webermann, A. R., \& Frankel, A. S. (2016). Assessment of complex dissociative disorder patients and simulated dissociation in forensic contexts. International Journal of Law and Psychiatry, 49(Pt B), 197-204. https://doi.org/10.1016/j.ijlp.2016.10.006.

Brand, B. L., Webermann, A. R., Snyder, B. L., \& Kaliush, P. R. (2019). Detecting clinical and simulated dissociative identity disorder with the test of memory malingering. Psychological Trauma: Theory, Research, Practice, and Policy, 11(5), 513-520. https://doi.org/10. $1037 /$ tra0000405.

Briere, J., Elliott, D. M., Harris, K., \& Cotman, A. (1995). Trauma symptom inventory: Psychometrics and association with childhood and adult trauma in clinical samples. Journal of Interpersonal Violence, $10,387-340$
Brown, D. W., Anda, R. F., Edwards, V. J., Felitti, V. J., Dube, S. R., \& Giles, W. H. (2007). Adverse childhood experiences and childhood autobiographical memory disturbance. Child Abuse and Neglect, 31(9), 961-969. https://doi.org/10.1016/j.chiabu.2007.02.011.

Brown, D. W., \& Scheflin, A. W. (1999). Factitious disorders and trauma-related diagnoses. Journal of Psychiatry and Law, 27(3-4), 373-422.

Brown, D. W., Scheflin, A. W., \& Whitfield, C. L. (1999). Recovered memories: The current weight of the evidence in science and in the courts. Journal of Psychiatry and Law, 27(2), 5-156.

Byun, S., Brumariu, L. E., \& Lyons-Ruth, K. (2016). Disorganized attachment in young adulthood as a partial mediator of relations between severity of childhood abuse and dissociation. Journal of Trauma and Dissociation, 17(4), 460-479. https://doi.org/10.1080/ 15299732.2016.1141149.

Cardena, E., Van Duijil, M., Weiner, L. A., \& Terhune, D. B. (2009). Possession/trance phenomena. In P. F. Dell \& J. A. O'Neil (Eds.), Dissociation and the dissociative disorders: DSM-V and beyond (pp. 171-180). New York: Routledge.

Carlson, E. A. (1998). A prospective longitudinal study of attachment disorganization/disorientation. Child Development, 69(4), 1107 1128.

Carlson, E. B., Dalenberg, C., \& McDade-Montez, E. (2012). Dissociation in posttraumatic stress disorder part I: Definitions and review of research. Psychological Trauma: Theory, Research, Practice, and Policy, 4(5), 479-489. https://doi.org/10.1037/ a0027748.

Chase, T. (1987). When rabbit howls. New York: E.P. Dutton.

Classen, C. C., Palesh, O. G., \& Aggarwal, R. (2005). Sexual revictimization: A review of the empirical literature. Trauma, Violence, \& Abuse, 6(2), 103-129. https://doi.org/10.1177/ 1524838005275087

Coons, P. M. (1989). Iatrogenic factors in the misdiagnosis of MPD. Dissociation, 2(2), 70-76.

Coons, P. M. (1991). Iatrogenesis and malingering of multiple personality disorder in the forensic evaluation of homicide defendents. Psychiatric Clinics of North America, 14, 757-768.

Coons, P. M., \& Milstein, V. (1994). Factitious or malingered multiple personality: Eleven cases. Dissociation, 7(2), 81-85.

Cooper, B. S., Kennedy, M. A., \& Yuille, J. C. (2001). Dissociation and sexual trauma in prostitutes. Journal of Trauma \& Dissociation, 2(2), 27-36. https://doi.org/10.1300/J229v02n02_03.

Dalenberg, C., \& Carlson, E. B. (2012). Dissociation in posttraumatic stress disorder part II: How theoretical models fit the empirical evidence andr recommendations for modifying the diagnostic criteria for PTSD. Psychological Trauma: Theory, Research, Practice, and Policy. https://doi.org/10.1037/a0027900.

Dalenberg, C. J., Brand, B. L., Gleaves, D. H., Dorahy, M. J., Loewenstein, R. J., Cardena, E., et al. (2012). Evaluation of the evidence for the trauma and fantasy models of dissociation. Psychological Bulletin, 138(3), 550-588. https://doi.org/10.1037/ a0027447.

Dalenberg, C. J., Glaser, D., \& Alhassoon, O. M. (2012). Statistical support for subtypes in posttraumatic stress disorder: The how and why of subtype analysis. Depression and Anxiety. https://doi.org/10. 1002/da.21926.

De Bellis, M. D., \& Putnam, F. W. (1994). The psychobiology of childhood maltreatment. Child and Adolescent Psychiatric Clinics of North America, 3, 663-678.

Dell, P. F. (2006a). The Multidimensional Inventory of Dissociation (MID): A comprehensive measure of pathological dissociation. Journal of Trauma and Dissociation, 7(2), 77-106 http://www. ncbi.nlm.nih.gov/entrez/query.fcgi? cmd=Retrieve \&db= PubMed\&dopt=Citation\&list uids=16769667. 
Dell, P. F. (2006b). A new model of dissociative identity disorder. Psychiatric Clinics of North America, 29(1), 1-26 http:// linkinghub.elsevier.com/retrieve/pii/s0193953x05000961.

Dell, P. F. (2009). The phenomena of pathological dissociation. In P. F. Dell \& J. A. O'Neil (Eds.), Dissociation and the dissociative disorders: DSM-V and beyond (pp. 225-238). New York: Rooutledge.

Dell, P. F. (2013). Three dimensions of dissociative amnesia. Journal of Trauma and Dissociation, 14(1), 25-39. https://doi.org/10.1080/ 15299732.2012.724762.

Dorahy, M. J., Brand, B. L., Sar, V., Kruger, C., Stavropoulos, P., Martinez-Taboas, A., et al. (2014). Dissociative identity disorder: An empirical overview. Australian and New Zealand Journal of Psychiatry, 48(5), 402-417. https://doi.org/10.1177/ 0004867414527523.

Draijer, N., \& Boon, S. (1999). The imitation of dissociative identity disorder: Patients at risk, therapists at risk. Journal of Psychiatry and Law, 27(3-4), 423-458.

Dube, S. R., Anda, R. F., Felitti, V. J., Chapman, D. P., Williamson, D. F., \& Giles, W. H. (2001). Childhood abuse, household dysfunction, and the risk of attempted suicide throughout the life span: Findings from the adverse childhood experiences study. Journal of the American Medical Association, 286, 3089-3096.

Farina, B., Liotti, M., \& Imperatori, C. (2019). The role of attachment trauma and disintegrative pathogenic processes in the traumaticdissociative dimension. Frontiers in Psychology, 10(933), 1-17. https://doi.org/10.3389/fpsyg.2019.00933.

Feldman, M., Mallouh, K., \& Lewis, D. O. (1986). Filicidal abuse in the histories of 15 condemned murderers. Bulletin of the American Academy of Psychiatry and the Law, 14, 345-352.

Felitti, V. J., \& Anda, R. F. (2010). The relationship of adverse childhood experiences to adult medical disease, psychiatric disorders and sexual behavior. In R. A. Lanius, E. Vermetten, \& C. Pain (Eds.), The hidden epidemic: The impact of early life trauma on health and disease (pp. 77-87). Cambridge, UK: Cambridge University Press.

Fine, C. G. (1989). Treatment errors and iatrogenesis accross therapeutic modalities in MPD and allied dissociative disorders. Dissociation, 2(2), 77-82.

Foote, B., Smolin, Y., Neft, D. I., \& Lipschitz, D. (2008). Dissociative disorders and suicidality in psychiatric outpatients. The Journal of Nervous and Mental Disease, 196(1), 29-36 http://www.ncbi.nlm. nih.gov/entrez/query.fcgi? $\mathrm{cmd}=$ Retrieve $\& \mathrm{db}=\mathrm{PubMed} \& \mathrm{dopt}=$ Citation\&list uids $=18195639$.

Ford, J. D., \& Gomez, J. M. (2015). The relationship of psychological trauma and dissociative and posttraumatic stress disorders to nonsuicidal self-injury and suicidality: A review. Journal of Trauma and Dissociation, 16(3), 232-271. https://doi.org/10.1080/ 15299732.2015 .989563$.

Freyd, J. J. (1996). Betrayal trauma: The logic of forgetting childhood abuse. Cambridge: Harvard.

Freyd, J. J. (1997). Violations of power, adaptive blindness, and betrayal trauma theory. Feminism \& Psychology, 7, 22-32.

Frischholz, E. J., Lipman, L. S., Braun, B. G., \& Sachs, R. G. (1992). Psychopathology, hypnotizability, and dissociation. American Journal of Psychiatry, 149, 1521-1525.

George, R. M. (2000). The hillside strangler trial. Loyola Law Review. 33 Loy. L.A. L. Review, pp. 705-724. Available at: https:// digitalcommons.lmu.edu/llr/vol33/iss2/9.

Gravely, S. D. (1982). The insanity defense in Virginia: An evaluation. University of Richmond Law Review, 17(1), 129-151.

Green, J. G., McLaughlin, K. A., Berglund, P. A., Gruber, M. J., Sampson, N., Zaslavsky, A. M., et al. (2010). Childhood adversities and adult psychiatric disorders in the national comorbidity survey replication I: Associations with first onset of DSM-IV disorders. Archives of General Psychiatry, 67(2), 113-123. https://doi.org/ 10.1001/archgenpsychiatry.2009.186.
Hafner, H., Maurer, K., Loffler, W., an der Heiden, W., Hambrecht, M., \& Schultze-Lutter, F. (2003). Modeling the early course of schizophrenia. Schizophrenia Bulletin, 29(2), 325-340.

Herman, J. L. (1993). Sequelae of prolonged and repeated trauma: Evidence for a complex posttraumatic syndrome (DESNOS). In J. R. T. Davidson \& E. B. Foa (Eds.), Posttraumatic stress disorder: DSM-IV and beyond (pp. 213-228). Washington, D.C.: American Psychiatric Press.

Herman, J. L. (2015). Trauma and recovery. New York: Basic Books.

Hornstein, N., \& Putnam, F. W. (1992). Clinical phenomenology of child and adolescent dissociative disorders. Journal of the American Academy of Child and Adolescent Psychiatry, 31, 1077-1085.

Imperatore, C., Innoamorati, M., Bersani, F. S., Imbimbo, F., Pompili, M., Contardi, A., et al. (2017). The association among childhood trauma, pathological dissociation and gambling severity in casino gamblers. Clinical Psychology \& Psychotherapy, 24(1), 203-211.

International Society for the Study of Dissociation, (Chu, J. A., Dell, P. F., Somer, E., Van der Hart, O., Cardeña, E., et al.). (2011). Guidelines for treating dissociative identity disorder in adults, third revision. Journal of Trauma and Dissociation, 12(2), 115-187. https://doi.org/10.1080/15299732.2011.537247.

Janet, P. (1887). The mental state of hystericals. New York: G.P. Putnam's Sons.

Janet, P. (1907). The major symptoms of hysteria. New York: The Macmillan Company.

Janet, P. (1924). Principles of psychotherapy (trans: H. M. Guthrie, \& E. R. Guthrie). Freeport, NY: Books for Libraries Press.

Johnson, J. G., Cohen, P., Kasen, S., \& Brook, J. S. (2006). Dissociative disorders among adults in the community, impaired functioning, and axis I and II comorbidity. Journal of Psychiatric Research, 40(2), 131-140. https://doi.org/10.1016/j.jpsychires.2005.03.003.

Karlin, R. A., \& Orne, M. T. (1996). Commentary on Borawick v. Shay: Hypnosis, social influence, incestuous child abuse, and satanic ritual abuse: The iatrogenic creation of horrific memories for the remote past. Cultic Studies Journal, 13(1), 42-94.

Kessler, R. C. (2000). Posttraumatic stress disorder: The burden to the individual and to society. Journal of Clinical Psychiatry, 61(suppl 5), 4-14.

Kessler, R. C., Berglund, P. A., Demler, O., Jin, R., Merikangas, K. R., \& Walters, E. E. (2005). Lifetime prevalence and age-of-onset distributions of DSM-IV disorders in the National Comorbidity Replication. Archives of General Psychiatry, 62, 593-602.

Kessler, R. C., Sonnega, A., Bromet, E., Hughes, M., \& Nelson, C. B. (1995). Posttraumatic stress disorder in the national comorbidity survey. Archives of General Psychiatry, 52, 1048-1060.

Kluemper, N. S., \& Dalenberg, C. (2014). Is the dissociative adult suggestible? A test of the trauma and fantasy models of dissociation. Journal of Trauma and Dissociation, 15(4), 457-476. https://doi. org/10.1080/15299732.2014.880772.

Kluft, R. P. (1985a). Childhood multiple personality disorder: Predictors, clinical findings, and treatment results. In R. P. Kluft (Ed.), Childhood antecedents of multiple personality (pp. 167-196). Washington D.C.: American Psychiatric Press.

Kluft, R. P. (1985b). The natural history of multiple personality disorder. In R. P. Kluft (Ed.), Childhood antecedents of multiple personality (pp. 197-238). Washington D.C.: American Psychiatric Press.

Kluft, R. P. (1986). High-functioning multiple personality patients: Three cases. Journal of Nervous and Mental Disease, 174(12), 722-726.

Kluft, R. P. (1987a). First rank symptoms as a diagnostic clue to multiple personality disorder. American Journal of Psychiatry, 144, 293 298.

Kluft, R. P. (1987b). The parental fitness of mothers with multiple personality disorder: A preliminary study. Child Abuse and Neglect, 11, $272-280$. 
Kluft, R. P. (1987c). The simulation and dissimulation of multiple personality disorder. American Journal of Clinical Hypnosis, 30, 104 118

Kluft, R. P. (1988). The phenomenology and treatment of extremely complex multiple personality disorder. Dissociation, 1(4), 47-58.

Kluft, R. P. (1989a). Iatrogenic creation of new alter personalities. Dissociation, 2(2), 83-91.

Kluft, R. P. (1989b). Treating the patient who has been sexually exploited by a previous therapist. Psychiatric Clinics of North America, 12, 483-500.

Kluft, R. P. (1990a). Dissociative disorders in impaired psychiatary residents and graduate students in psychology. Dissocation, 3(1), 4853.

Kluft, R. P. (1990b). Incest and subsequent revictimaization: The case of therapist-patient sexual exploitation, with a description of the sitting duck syndrome. In Incest-related disorders of adult psychopathology (pp. 263-289). Washington D.C.: American Psychiatric Press.

Kluft, R. P. (1990c). Preliminary notes on MPD and allied forms of dissociative disorder not otherwise specified in practicing psychotherapists. Dissocation, 3(2), 113-122.

Kluft, R. P. (1991). Clinical presentations of multiple personality disorder. Psychiatric Clinics of North America, 14, 605-629.

Kluft, R. P. (1992). Enhancing the hospital treatment of dissociative patients by developing nursing expertise in the application of hypnotic techniques without formal trance induction. American Journal of Clinical Hypnosis, 34, 158-167.

Kluft, R. P. (1993). Basic principles in conducing the psychotherapy of multiple personality disorder. In R. P. Kluft \& C. G. Fine (Eds.), Clinical perspectives on multiple personality disorder (pp. 19-50). Washington D.C: American Psychiatric Press.

Kluft, R. P. (1994a). Countertransference in the treatment of multiple personality disorder. In J. P. Wilson \& J. D. Lindy (Eds.), Countertransference in the treatment of trauma (pp. 122-150). New York: Guilford.

Kluft, R. P. (1994b). Treatment trajectories in multiple personality disorder. Dissociation, 7, 63-76.

Kluft, R. P. (1997). The argument for the reality of the delayed recall of trauma. In P. S. Applebaum, L. A. Uyehara, \& M. Elin (Eds.), Trauma and memory: Clinical and legal controversies (pp. 2557). New York: Oxford University Press.

Kluft, R. P. (2005). Diagnosing dissociative identity disorder. Psychiatric Annals, 35(8), 633-643.

Kluft, R. P. (2006). Dealing with alters: A pragmatic clinical perspective. Psychiatric Clinics of North America, 29(1), 281-304 http:// linkinghub.elsevier.com/retrieve/pii/s0193953x05000936.

Kluft, R. P. (2007a). Applications of innate affect theory to the understanding and treatment of dissociative identity disorder. In E. Vermetten, M. Dorahy, \& D. Spiegel (Eds.), Traumatic dissociation (pp. 301-316). Washington, D.C.: American Psychiatric Press.

Kluft, R. P. (2007b). The older female patient with a complex chronic dissociative disorder. Journal of Women and Aging, 19(1-2), 119137. https://doi.org/10.1300/J074v19n01_08.

Kluft, R. P. (2012). Hypnosis in the treatment of dissociative identity disorder and allied states: An overview and case study. South Africa Journal of Psychology, 42(2), 146-155.

Kluft, R. P. (2013). Shelter from the storm: Processing the traumatic memories of DID/DDNOS patients with the fractionated abreaction technique (A vademecum for the treatment of DID/DDNOS). CreateSpace Independent Publishing Platform.

Kluft, R. P., \& Loewenstein, R. J. (2007). Dissociative disorders and depersonalization. In G. O. Gabbard (Ed.), Gabbard's treatment of psychiatric disorders (pp. 547-572). Washington, D.C.: American Psychiatric Publishing.

Kritchevsky, M., Chang, J., \& Squire, L. R. (2004). Functional amnesia: Clinical description and neuropsychological profile of 10 cases.
Learning and Memory, 11(2), 213-226 http://www.ncbi.nlm.nih. gov/entrez/query.fcgi?cmd=Retrieve $\& \mathrm{db}=\mathrm{PubMed} \& \mathrm{dopt}=$ Citation\&list uids $=15054137$.

Laddis, A., \& Dell, P. F. (2012). Dissociation and psychosis in dissociative identity disorder and schizophrenia. Journal of Trauma and Dissociation, 13(4), 397-413. https://doi.org/10.1080/15299732. 2012.664967.

Laddis, A., Dell, P. F., \& Korzekwa, M. (2017). Comparing the symptoms and mechanisms of "dissociation" in dissociative identity disorder and borderline personality disorder. Journal of Trauma and Dissociation, 18(2), 139-173. https://doi.org/10.1080/15299732. 2016.1194358.

Lanius, R., \& Frewen, P. (2015). Healing the traumatized self: Consciousness, neuroscience treatment. New York: Norton.

LeBouthillier, D. M., McMillan, K. A., Thibodeau, M. A., \& Asmundson, G. J. (2015). Types and number of traumas associated with suicidal ideation and suicide attempts in PTSD: Findings from a U.S. nationally representative sample. Journal of Traumatic Stress, 28(3), 183-190. https://doi.org/10.1002/jts.22010.

Lewis, D. O., \& Bard, J. S. (1991). Multiple personality and forensic issues. Psychiatric Clinics of North America, 14, 741-756.

Lewis, D. O., \& Yeager, C. A. (1996). The intergenerational transmission of violence and dissociation. In D. O. Lewis \& F. W. Putnam (Eds.), Dissociative identity disorder/multiple personality disorder: Child and adolescent psychiatric clinics of North America (pp. 393-430). Philadelphia: Saunders.

Lewis, D. O., Yeager, C. A., Swica, Y., Pincus, J. H., \& Lewis, M. (1997). Objective documentation of child abuse and dissociation in 12 murderers with dissociative identity disorder. American Journal of Psychiatry, 154, 1703-1710.

Lewis-Fernandez, R., Guarnaccia, P. J., \& Ruiz, P. (2009). Culture bound syndromes. In H. Kaplan \& B. Sadock (Eds.), Comprehensive textbook of psychiatry (pp. 2519-2538). New York: Lippincott, Williams \& Wilkins.

Lilienfeld, S. O., Kirsch, I., Sarbin, T. R., Lynn, S. J., Chaves, J. F., \& Ganaway, G. K. (1999). Dissociative identity disorder and the sociocognitive model: Recalling the lessons of the past. Psychological Bulletin, 125, 507-523.

Liotti, G. (2009). Attachment and dissociation. In P. F. Dell \& J. A. O'Neil (Eds.), Dissociation and the dissociative disorders: DSM-V and beyond (pp. 53-65). New York: Routledge.

Loewenstein, R. J. (1991a). An office mental status examination for chronic complex dissociative symptoms and multiple personality disorder. Psychiatric Clinics of North America, 14, 567-604.

Loewenstein, R. J. (1991b). Rational psychopharmacology for multiple personality disorder. Psychiatric Clinics of North America, 14, 721740.

Loewenstein, R. J. (1993). Posttraumatic and dissociative aspects of transference and countertransference in the treatment of multiple personality disorder. In R. P. Kluft \& C. G. Fine (Eds.), Clinical perspectives on multiple personality disorder (pp. 51-85). Washington D.C: American Psychiatric Press.

Loewenstein, R. J. (1994). Diagnosis, epidemiology, clinical course, treatment, and cost effectiveness of treatment for dissociative disorders and multiple personality disorder: Report submitted to the Clinton administration task force on health care financing reform. Dissociation, 7(1), 3-11.

Loewenstein, R. J. (2005). Psychopharmacologic treatments for dissociative identity disorder. Psychiatric Annals, 35(8), 666-673.

Loewenstein, R. J. (2007). Dissociative identity disorder: Issues in the iatrogenesis controversy. In E. Vermetten, M. Dorahy, \& D. Spiegel (Eds.), Traumatic dissociation (pp. 275-299). Washington, D.C.: American Psychiatric Press.

Loewenstein, R. J. (2014). Treatment of dissociative amnesia. In G. O. Gabbard (Ed.), Gabbard's treatment of psychiatric disorders (pp. 471-478). Washington, D.C.: American Psychiatric Publishing. 
Loewenstein, R. J. (2018). Dissociation debates: Everything you know is wrong. Dialogues in Clinical Neuroscience, 20(3), 229-242.

Loewenstein, R. J., Frewen, P. A., \& Lewis-Fernández, R. (2017). Dissociative disorders. In B. J. Sadock, V. A. Sadock, \& P. Ruiz (Eds.), Kaplan \& Sadock's comprehensive textbook of psychiatry (pp. 1866-1952). Philadelphia, PA: Wolters Kluwer/ Lippincott Williams \& Wilkens.

Loewenstein, R. J., Hamilton, J., Alagna, S., Reid, N., \& deVries, M. (1987). Experiential sampling in the study of multiple personality disorder. American Journal of Psychiatry, 144, 19-24.

Loewenstein, R. J., \& Putnam, F. W. (1990). The clinical phenomenology of males with multiple personality disorder. Dissociation, 3, 135143.

Loewenstein, R. J., \& Ross, D. (1992). Multiple personality and psychoanalysis: An introduction. Psychoanalytic Inquiry, 12, 3-48.

Loewenstein, R. J., \& Wait, S. B. (2008). The trauma disorders unit. In S. S. Sharfstein, F. B. Dickerson, \& J. M. Oldham (Eds.), Textbook of hospital psychiatry (pp. 103-118). Washington DC: American Psychiatric Press.

Loewenstein, R. J., \& Welzant, V. (2010). Pragmatic approaches to stage oriented treatment for early life trauma related complex posttraumatic stress and dissociative disorders. In R. A. Lanius, E. Vermetten, \& C. Pain (Eds.), The hidden epidemic: The impact of early life trauma on health and disease (pp. 257-267). Cambridge, UK: Cambridge University Press.

Longden, E., House, A. O., \& Waterman, M. G. (2016). Associations between nonauditory hallucinations, dissociation, and childhood adversity in first-episode psychosis. Journal of Trauma and Dissociation, 17(5), 545-560. https://doi.org/10.1080/15299732. 2016.1155193.

Longden, E., Madill, A., \& Waterman, M. G. (2012). Dissociation, trau$\mathrm{ma}$, and the role of lived experience: Toward a new conceptualization of voice hearing (review). Psychological Bulletin, 138(1), 28 76. https://doi.org/10.1037/a0025995.

Lustman, J. (1977). On splitting. The Psychoanalytic Study of the Child, $32,119-154$.

Lyons-Ruth, K. (2008). Contributions of the mother-infant relationship to dissociative, borderline, and conduct symptoms in young adulthood. Infant Mental Health Journal, 29(3), 203-218. https://doi.org/10. 1002/imhj.20173.

Lyons-Ruth, K., Dutra, L., Schuder, M. R., \& Bianchi, I. (2006). From infant attachment disorganization to adult dissociation: Relational adaptations or traumatic experiences? Psychiatric Clinics of North America, 29(1), 63-86 http://linkinghub.elsevier.com/retrieve/pii/ s0193953x05000948.

Lyssenko, L., Schmahl, C., Bockhacker, L., Vonderlin, R., Bohus, M., \& Kleindienst, N. (2017). Dissociation in psychiatric disorders: A meta-analysis of studies using the dissociative experiences scale. American Journal of Psychiatry, 17, appiajp201717010025. https://doi.org/10.1176/appi.ajp.2017.17010025.

Maaranen, P., Tanskanen, A., Hintikka, J., Honkalampi, K., Haatainen, K., Koivumaa-Honkanen, H., et al. (2008). The course of dissociation in the general population: A 3-year follow-up study. Comprehensive Psychiatry, 49(3), 269-274. https://doi.org/10. 1016/j.comppsych.2007.04.010.

Mao, F. (2019, September 6, 2019). Dissociative identity disorder: The woman who created 2,500 personalities to survive, online news article. BBC News - Australia. Retrieved from https://www.bbc. com/news/world-australia-49589160.

McHugh, P. (1995). Witches, multiple personalites, and other psychiatric artifacts. Nature Medicine, 1, 110-114.

McLaughlin, K. A., Green, J. G., Gruber, M. J., Sampson, N. A., Zaslavsky, A. M., \& Kessler, R. C. (2010). Childhood adversities and adult psychiatric disorders in the national comorbidity survey replication II: Associations with persistence of DSM-IV disorders.
Archives of General Psychiatry, 67(2), 124-132. https://doi.org/10. 1001/archgenpsychiatry.2009.187.

Merckelbach, H., \& Patihis, L. (2018). Why "trauma-related dissociation" is a misnomer in courts: A critical analysis of Brand et al. (2017a, b). Psychological Injury and Law. https://doi.org/10.1007/ s12207-018-9328-8.

Middleton, W. (2013). Ongoing incestuous abuse during adulthood. Journal of Trauma and Dissociation, 14(3), 251-272. https://doi. org/10.1080/15299732.2012.736932.

Mueller-Pfeiffer, C., Rufibach, K., Perron, N., Wyss, D., Kuenzler, C., Prezewowsky, C., et al. (2012). Global functioning and disability in dissociative disorders. Psychiatry Research, 200(2-3), 475-481. https://doi.org/10.1016/j.psychres.2012.04.028.

Myers, C. S. (1915). A contribution to the study of shell-shock. Lancet, 316-320.

Myers, C. S. (1916). Contributions to the study of shell-shock. Lancet, 65-69.

Myers, C. S. (1940). Shell shock in France 1914-1918. Cambridge: Cambridge University Press.

Myrick, A. C., Brand, B. L., \& Putnam, F. W. (2013). For better or worse: The role of revictimization and stress in the course of treatment for dissociative disorders. Journal of Trauma and Dissociation, 14(4), 375-389. https://doi.org/10.1080/15299732.2012.736931.

Naish, P. (2013). Hallucinations in hypnosis. In F. Macpherson \& D. Platchia (Eds.), Hallucination: Philosophy and psychology (pp. 121-148). Cambridge, MA: The MIT Pewaa.

Nijehuis, E. R. S. (2014). Ten reasons for conceiving and classifying posttraumatic stress disorder as a dissociative disorder. Psichiatria e Psicoterapia, 33(1), 74-106.

Noll, J. G., Horowitz, L. A., Bonanno, G. A., Trickett, P. K., \& Putnam, F. W. (2003). Revictimization and self-harm in females who experienced childhood sexual abuse: Results from a prospective study. Journal of Interpersonal Violence, 18(12), 1452-1471.

Nordgaard, J., Arnfred, S. M., Handest, P., \& Parnas, J. (2008). The diagnostic status of first-rank symptoms. Schizophrenia Bulletin, 34(1), 137-154. https://doi.org/10.1093/schbul/sbm044.

Ogawa, J. R., Sroufe, L. A., Weinfeld, N. S., Carslson, E. A., \& Egeland, B. (1997). Development and the fragmented self: Longitudinal study of dissociative symptomatology in a nonclinical sample. Development and Psychopathology, 9, 855-879.

Olafson, E., Boat, B. W., Putnam, K. T., Thieken, L., Marrow, M. T., \& Putnam, F. W. (2018). Implementing trauma and grief component therapy for adolescents and think trauma for traumatized youth in secure juvenile justice settings. Journal of Interpersonal Violence, 33(16), 2537-2557. https://doi.org/10.1177/0886260516628287.

Orne, M. T., Dinges, D. F., \& Orne, E. C. (1984). On the differential diagnosis of multiple personality in the forensic context. International Journal of Clinical and Experimental Hypnosis, 32(2), 118-169. https://doi.org/10.1080/00207148408416007.

Orne, M. T., Whitehouse, W. G., Dinges, D. F., \& Orne, E. C. (1988). Reconstructing memory through hypnosis: Forensic and clinical implications. In H. M. Pettinati (Ed.), Hypnosis and memory (pp. 2163). New York: Guilford.

Palermo, C. A., \& Brand, B. L. (2019). Can the trauma symptom Inventory-2 distinguish coached simulators from dissociative disorder patients? Psychological Trauma: Theory, Research Practice and Policy, 11(5), 477-485. https://doi.org/10.1037/tra0000382.

Park, S. H., Videlock, E. J., Shih, W., Presson, A. P., Mayer, E. A., \& Chang, L. (2016). Adverse childhood experiences are associated with irritable bowel syndrome and gastrointestinal symptom severity. Neurogastroenterology Motility, 28(8), 1252-1260. https://doi. org/10.1111/nmo.12826.

Pilton, M., Varese, F., Berry, K., \& Bucci, S. (2015). The relationship between dissociation and voices: A systematic literature review and meta-analysis. Clinical Psychology Review, 40, 138-155. https:// doi.org/10.1016/j.cpr.2015.06.004. 
Pope, K. S. (1989). Therapist-patient sex syndrome: A guide for attorneys and subsequent therapists to assessing damage. In G. O. Gabbard (Ed.), Sexual exploitation in professional relationships. Washington DC: American Psychiatric Press.

Putnam, F. W. (1988). The switch process in multiple personality disorder and other state-change disorders. Dissociation, 1, 24-32.

Putnam, F. W. (1989). Diagnosis and treatment of multiple personality disorder. New York: Guilford.

Putnam, F. W. (1997). Dissociation in children and adolescents: A developmental model. New York: Guilford.

Putnam, F. W. (2006). The impact of trauma on child development. Juvenile \& Family Court Journal, 57(1), 1-11.

Putnam, F. W. (2016). The way we are: How states of mind influence our identities, personality, and potential for change. New York: IUP.

Putnam, F. W., Hornstein, N., \& Peterson, G. (1996). Clinical phenomenology of child and adolescent dissociative disorders. In D. O. Lewis \& F. W. Putnam (Eds.), Dissociative identity disorder/ multiple personality disorder: Child and adolescent psychiatric clinics of North America (pp. 351-373). Philadelphia: Saunders.

Putnam, K. T., Harris, W. W., \& Putnam, F. W. (2013). Synergistic childhood adversities and complex adult psychopathology. Journal of Traumatic Stress, 26(4), 435-442. https://doi.org/10. $1002 /$ jts. 21833.

Reinders, A. A., Willemsen, A. T., den Boer, J. A., Vos, H. P., Veltman, D. J., \& Loewenstein, R. J. (2014). Opposite brain emotionregulation patterns in identity states of dissociative identity disorder: A PET study and neurobiological model. Psychiatry Research: Neuroimaging Section, 223(3), 236-243. https://doi.org/10.1016/j. pscychresns.2014.05.005.

Reinders, A. A., Willemsen, A. T., Vissia, E. M., Vos, H. P., den Boer, J. A., \& Nijenhuis, E. R. (2016). The psychobiology of authentic and simulated dissociative personality states: The Full Monty. Journal of Nervous and Mental Disease, 204(6), 445-457. https://doi.org/10. 1097/NMD.0000000000000522.

Rogers, R., Bagby, R. M., \& Dickens, S. E. (1992). Structured interview of reported symptoms: Professional manual. Lutz, FL: Psychological Assessment Resources.

Ross, C. A., Ferrell, L., \& Schroeder, E. (2014). Co-occurrence of dissociative identity disorder and borderline personality disorder. Journal of Trauma and Dissociation, 15(1), 79-90. https://doi.org/10.1080/ 15299732.2013 .834861$.

Ross, C. A., \& Joshi, S. (1992). Schneiderian symptoms and childhood trauma in the general population. Comprehensive Psychiatry, 33(4), 269-273.

Ross, C. A., Miller, S. D., Reagor, P., Bjornson, L., Fraser, G. A., \& Anderson, G. (1990). Schneiderian symptoms in multiple personality disorder and schizophrenia. Comprehensive Psychiatry, 31, 111118.

Ross, C. A., Schroeder, E., \& Ness, L. (2013). Dissociation and symptoms of culture-bound syndromes in North America: A preliminary study. Journal of Trauma and Dissociation, 14(2), 224-235. https:// doi.org/10.1080/15299732.2013.724338.

Ryder, A. G., Yang, J., Zhu, X., Yao, S., Yi, J., Heine, S. J., et al. (2008). The cultural shaping of depression: Somatic symptoms in China, psychological symptoms in North America? Journal of Abnormal Psychology, 117(2), 300-313. https://doi.org/10.1037/0021-843X. 117.2.300.

Saks, E. R. (1997). Jekyll on trial: Multiple personality and criminal law. New York: New York University.

Salter, M. (2017). Organized abuse in adulthood: Survivor and professional perspectives. Journal of Trauma and Dissociation, 18(3), 441-453. https://doi.org/10.1080/15299732.2017.1295426.

Saltzman, W., Layne, C. M., Pynoos, R., Olafson, E., Kaplow, J., \& Boat, B. W. (2017). Trauma and grief-component therapy for adolescents: A modular approach to treating traumatized and bereaved youth. Cambridge, UK: Cambridge University Press.
Sar, V., Alioglu, F., \& Akyuz, G. (2014). Experiences of possession and paranormal phenomena among women in the general population: Are they related to traumatic stress and dissociation? Journal of Trauma and Dissociation, 15(3), 303-318. https://doi.org/10.1080/ 15299732.2013.849321.

Sar, V., Alioglu, F., \& Akyuz, G. (2017). Depersonalization and derealization in self-report and clinical interview: The spectrum of borderline personality disorder, dissociative disorders, and healthy controls. Journal of Trauma and Dissociation, 18(4), 490-506. https://doi.org/10.1080/15299732.2016.1240737.

Sar, V., Alioglu, F., Akyuz, G., \& Karabulut, S. (2014). Dissociative amnesia in dissociative disorders and borderline personality disorder: Self-rating assessment in a college population. Journal of Trauma and Dissociation, 15(4), 477-493. https://doi.org/10.1080/ 15299732.2014 .902415

Sar, V., Alioglu, F., Akyuz, G., Tayakisi, E., Ogulmus, E. F., \& Sonmez, D. (2017). Awareness of identity alteration and diagnostic preference between borderline personality disorder and dissociative disorders. Journal of Trauma and Dissociation, 18(5), 693-709. https:// doi.org/10.1080/15299732.2016.1267684.

Schaffler, Y., Cardena, E., Reijman, S., \& Haluza, D. (2015). Traumatic experience and somatoform dissociation among spirit possession practitioners in the Dominican Republic. Culture, Medicine and Psychiatry. https://doi.org/10.1007/s11013-015-9472-5.

Schalinski, I., \& Teicher, M. H. (2015). Type and timing of childhood maltreatment and severity of shutdown dissociation in patients with schizophrenia spectrum disorder. PLoS One, 10(5), e0127151. https://doi.org/10.1371/journal.pone.0127151.

Schreiber, F. R. (1976). Sybil. Chicago: Regnery.

Scott, C. L. (2012). Evaluating amnesia for criminal behavior: A guide to remember. Psychiatric Clinics of North America, 35(4), 797-819. https://doi.org/10.1016/j.psc.2012.08.003.

Silberg, J. L. (2000). Fifteen years of dissociation in maltreated children: Where do we go from here? Child Maltreatment, 5(2), 119-136.

Silberg, J. L. (2004). The treatment of dissociation in sexually abused children from a family/attachment perspective. Psychotherapy: Theory, Research, Practice, Training, 41(4), 487-495. https://doi. org/10.1037/0033-3204.41.4.487.

Silberg, J. L. (2013). The child survivor: Healing developmental trauma and dissociation. New York and London: Routledge.

Silberg, J. L., \& Dallam, S. (2009). Dissociation in children and adolescents: At the crossroads. In P. F. Dell \& J. A. O'Neil (Eds.), Dissociation and the dissociative disorders: DSM-V and beyond (pp. 67-81). New York: Routledge.

Simeon, D., \& Loewenstein, R. J. (2009). Dissociative disorders. In B. J. Sadock, V. A. Sadock, \& P. Ruiz (Eds.), Comprehensive textbook of psychiatry (pp. 1965-2026). Philadelphia, PA: Wolters Kluwer/ Lippinoctt Williams \& Wilkens.

Sinnott-Armstrong, W., \& Behneke, S. H. (2001). Criminal law and multiple personality disorder: The vexing problems of personhood and responsibility. Southern California Interdisciplanary Law Journal, 10(2), 277-296.

Snyder, B. L. (2018). Women with dissociative identity disorder who experience intimate partner violence. Journal of Psychosocial Nursing and Mental Health Services, 56(5), 26-32.

Spiegel, D., Loewenstein, R. J., Lewis-Fernandez, R., Sar, V., Simeon, D., Vermetten, E., et al. (2011). Dissociative disorders in DSM-5. Depression and Anxiety, 28(9), 824-852. https://oi.org/10.1002/ da.20874.

Staniloiu, A., \& Markowitsch, H. J. (2014). Dissociative amnesia. The Lancet Psychiatry, 1(3), 226-241. https://doi.org/10.1016/s22150366(14)70279-2.

Staniloiu, A., Markowitsch, H. J., \& Kordon, A. (2018). Psychological causes of autobiographical amnesia: A study of 28 cases. Neuropsychologia, 110, 134-147. https://doi.org/10.1016/j. neuropsychologia.2017.10.017. 
Steele, K., van der Hart, O., \& Nijehhuis, E. R. S. (2009). The theory of trauma-related structural dissociation. In P. F. Dell \& J. A. O'Neil (Eds.), Dissociation and the dissociative disorders: DSM-V and beyond (pp. 239-258). New York: Routledge.

Stein, D. J., Koenen, K. C., Friedman, M. J., Hill, E. M., McLaughlin, K. A., Petukhova, M., et al. (2013). Dissociation in posttraumatic stress disorder: Evidence from the world mental health surveys. Biological Psychiatry, 73(4), 302-312 http://linkinghub.elsevier.com/retrieve/ pii/S0006322312007718?showall=true.

Steinberg, M. (1994). The structured clinical interview for DSM-IV Dissociative Disorders-Revised (SCID-D-R). Washington, D.C.: American Psychiatric Press.

Takahashi, Y. (1988). Aokigahara-jukai: Suicide and amnesia in Mt. Fuji's black forest. Suicide and Life Threatening Behavior, 18, 164-175.

Thomas, A. (2001). Factitious and malingered dissociative identity disorder: Clinical features observed in 18 cases. Journal of Trauma and Dissociation, 2(4), 59-77.

Trickett, P. K., Noll, J. G., \& Putnam, F. W. (2011). The impact of sexual abuse on female development: Lessons from a multigenerational, longitudinal research study. Development and Psychopathology, 23(02), 453-476. https://doi.org/10.1017/s0954579411000174.

Trujillo, K., Lewis, D. O., Yeager, C. A., \& Gidlow, B. (1996). Imaginary companions of school boys and boys with dissociatuve identity disorder/multiple personality disorder: A normal to pathologic continuum. In D. O. Lewis \& F. W. Putnam (Eds.), Dissociative identity disorder/multiple personality disorder: Child and adolescent psychiatric clinics of North America (pp. 375-391). Philadelphia: Saunders.

Tung, T. H., Hsiao, Y. Y., Shen, S. A., \& Huang, C. (2019). The prevalence of mental disorders in Taiwanese prisons: A nationwide population-based study. Social Psychiatry and Psychiatric Epidemiology, 54(3), 379-386. https://doi.org/10.1007/s00127018-1614-y.

Vaillant, G. E. (1975). Sociopathy as a human process: A viewpoint. Archives of General Psychiatry, 32(2), 178-183. https://doi.org/ 10.1001/archpsyc.1975.01760200042003.

van der Hart, O., \& Friedman, B. (1989). A reader's guide to Pierre Janet on dissociation: A neglected intellectual heritage. Dissociation, 2(1), 3-16.

van der Hart, O., Nijenhuis, E. R. S., \& Steele, K. (2006). The haunted self. New York: W.W. Norton \& Co..

Van Duijl, M., Nijenhuis, E., Komproe, I. H., Hajo, B. P., Gernaat, E., \& De Jong, J. T. M. V. (2010). Dissociative symptoms and reported trauma among patients with spirit possession and matched healthy controls in Uganda. Culture of Medicine and Psychiatry, 34(2), 380-400. https://doi.org/10.1007/s11013-010-9171-1.

van Ijzendoorn, M. H., \& Schuengel, C. (1996). The measurement of dissociation in normal and clinical populations: Meta-analytic validation of the dissociative experiences scale (DES). Clinical Psychology Review, 16(5), 365-382.

Vissia, E. M., Giesen, M. E., Chalavi, S., Nijenhuis, E. R., Draijer, N., Brand, B. L., et al. (2016). Is it trauma- or fantasy-based?
Comparing dissociative identity disorder, post-traumatic stress disorder, simulators, and controls. Acta Psychiatrica Scandinavica, 134(2), 111-128. https://doi.org/10.1111/acps.12590.

Waller, N. G., Putnam, F. W., \& Carlson, E. B. (1996). Types of dissociation and dissociative types: A taxonometric analysis of dissociative experiences. Psychological Methods, 1(3), 300-321.

Watkins, J. G. (1976). Ego states and the problem of criminal responsibility: A pyschological analysis of the Patty Hearst case. Journal of Psychiatry and Law, 2, 471-489.

Watkins, J. G. (1984). The Bianchi (L.A. Hillside Strangler) case; sociopath or multiple personality? International Journal of Clinical and Experimental Hypnosis, 32, 67-101.

Watkins, J. G., \& Watkins, H. H. (1984). Hazards to the therapist in the treatment of multiple personalities. Psychiatric Clinics of North America, 7(1), 111-119.

Watkins, J. G., \& Watkins, H. H. (1988). The management of malevolent ego states in multiple personality disorder. Dissociation, 1, 67-72.

Webermann, A. R., Brand, B. L., \& Chasson, G. S. (2014). Childhood maltreatment and intimate partner violence in dissociative disorder patients. European Journal of Psychotraumatology, 5, 1-8. https:// doi.org/10.3402/ejpt.v5.24568.

Webermann, A. R., Brand, B. L., \& Kumar, S. A. (2017). Intimate partner violence among patients with dissociative disorders. Journal of Interpersonal Violence, 886260517746943. https://doi.org/10. $1177 / 0886260517746943$.

Webermann, A. R., Myrick, A. C., Taylor, C. L., Chasson, G. S., \& Brand, B. L. (2016). Dissociative, depressive, and PTSD symptom severity as correlates of nonsuicidal self-injury and suicidality in dissociative disorder patients. Journal of Trauma and Dissociation, 17(1), 67-80. https://doi.org/10.1080/15299732. 2015.1067941.

Weierich, M. R., \& Nock, M. K. (2008). Posttraumatic stress symptoms mediate the relation between childhood sexual abuse and nonsuicidal self-injury. Journal of Consulting and Clinical Psychology, 76(1), 39-44. https://doi.org/10.1037/0022-006X.76. 1.39 .

Whitfield, C. L., Dube, S. R., Felitti, V. J., \& Anda, R. F. (2005). Adverse childhood experiences and hallucination. Child Abuse and Neglect, 29(7), 797-810.

Wilgus, S. J., Packer, M. M., Lile-King, R., Miller-Perrin, C. L., \& Brand, B. L. (2015). Coverage of child maltreatment in abnormal psychology textbooks: Reviewing the adequacy of the content. Psychological Trauma: Theory, Research, Practice and Policy. https://doi.org/10.1037/tra0000049.

World Health Organization. (1992). The ICD-10 classification of mental and behavioural disorders: Clinical descriptions and diagnostic guidelines. Geneva, Switzerland: WHO.

Yalom, I. D. (1989). Therapeutic monogamy. Love's executioner and other tales of psychotherapy. New York: Basic Books.

Publisher's Note Springer Nature remains neutral with regard to jurisdictional claims in published maps and institutional affiliations. 